\title{
Rational design and development of HDAC inhibitors for breast cancer treatment
}

Deepansh Mody ${ }^{1}$, Julie Bouckaert ${ }^{2}$, Savvas N. Savvides $^{3}$, and Vibha Gupta ${ }^{1, \#}$

${ }^{1}$ Department of Biotechnology, Jaypee Institute of Information Technology, A-10, Sector-62, Noida, UP, 201307, India

${ }^{2}$ Unité de Glycobiologie Structurale et Fonctionnelle (UGSF), Univ. Lille, CNRS, UMR 8576, 59658 Villeneuve d'Ascq, France

${ }^{3}$ Unit for Structural Biology, VIB - UGent Center for Inflammation Research, Department of Biochemistry and Microbiology, Ghent University, Technologiepark 71, 9052 Ghent, Belgium.

Running Title: Rational structure-based discovery of HDAC inhibitors against breast cancer

\section{\#Corresponding Author:}

Dr. Vibha Gupta

Associate Professor,

Department of Biotechnology, Jaypee Institute of Information Technology

Sector-62, Noida, UP, 201307, India

Phone : (+91) -120-2594-207

Email : vibha.gupta@jiit.ac.in 


\section{Structured Abstract:}

Background: Breast cancer is the most prevalent cancer amongst females across the globe and with over 2 million new cases reported in 2018, it poses huge economic burden to the already dwindling public health. A dearth of therapies in the pipeline to treat triple-negative breast cancers, and acquisition of resistance against existing line of treatments urges the need to strategize novel therapeutics in order to add new drugs to the pipeline. HDAC inhibitors (HDACi) is one such class of small molecule inhibitors that target histone deacetylases to bring about chromosomal remodelling and normalize dysregulated gene expression that marks breast cancer progression.

Objective: While four HDACi have been approved by the FDA for treatment of different cancer types, no HDACi is specifically earmarked for clinical management of breast cancer. Owing to the differential HDAC expression pertaining to different types of breast cancers, isoformselective HDAC inhibitors need to be discovered.

Conclusion: This review attempts to set the stage for rational structure-based discovery of isoform-selective HDACi by providing structural insights into different HDACs and their catalytic folds based on their classes and individual landscape. Development of inhibitors in accordance with the differential expression of HDAC isoforms exhibited in breast cancer cells is a promising strategy to rationally design selective and effective inhibitors, adopting a 'personalized-medicine' approach.

Keyword(s): Histone deacetylases, HDACi, rational drug discovery, structural insights, breast cancer, differential HDAC expression, HDAC-isoform selectivity 


\section{Introduction}

The increasing burden of cancer is a major health concern worldwide. As the most prevalent cancer type amongst females, the past decade witnessed a $20 \%$ increase in the rate of incidence of breast cancer, accompanied by a $14 \%$ increase in related mortality (1). With 2.1 million new cases reported in 2018, accounting for an estimated 630,000 deaths worldwide, the global breast cancer burden on healthcare systems is expected to rise enormously by 2040, especially in developing and under-developed nations (2). Histology and staging of breast cancer originate from heterogeneous factors involving various genetic mutations and atypical amplifications of both, oncogenes and tumor suppressor genes (3). Profiling of oncogenic expression based on molecular diversification has classified breast cancers into five intrinsic subtypes. Unusual expression of hormonal Estrogen receptor (ER) and Progesterone receptor (PR), along with human epidermal growth factor receptor 2 (HER2) is involved in causing luminal A and luminal B ER positive, HER2 enriched, normal-like, and basal-like breast cancers (4). Identification and understanding of such molecular marks have paved the way for several FDA-approved targeted hormone therapies against breast cancer (5). However, present proto-oncogenic therapies fall short in focused treatment of triple-negative breast cancer (TNBC) cells that do not display any of the ER, PR, or HER2 proto-oncogenic receptors, while also leading to de novo development or acquisition of resistance when administered on receptor positive cells, thereby promoting tumor recurrence. Development of resistance against anticancer drugs is a major obstacle in advancing the management of sophisticated breast cancers with metabolic variants (6), and has obligated the need for continued explorations to advance the understanding of factors that promote breast cancer tumorigenesis and drug resistance, so as to strategize novel anticancer drugs.

Several intrinsic and acquired factors are involved in altering molecular pathways that promote breast cancer tumorigenicity, of which epigenetic modifications account for transient and reversible alterations in gene expression without any particular changes in the genetic code. Such modifications can occur on DNA, non-coding RNA (ncRNA), and/ or histones to facilitate structural adaptation of chromosomal regions to keep up with altered activity states (7). Remodeling of nucleosomes by DNA methylation and histone modification has been reported to be involved in malignant transformation of normal cells by transcriptional silencing of critical tumor-suppressor genes in various cancers, including breast cancer (8). A family of DNA methyltransferases (DNMTs), comprising of DNMT1, DNMT3a, and DNMT3b catalyze the transfer of a methyl group to cytosine residues of the widely studied $\mathrm{CpG}$ islands in promoter region at 5'PO4 end (8). Methylation of these islands promotes chromatin condensation, leading to transcriptional silencing of gene expression, thereby making hypermethylation of otherwise unmethylated $\mathrm{CpG}$ islands a characteristic feature of cancer cells (9). Conversely, on histone level, chromatin remodeling is reliant on post-translational modifications (PTMs) which can either occur in the catalytic domain formed by four core proteins H2A, H2B, H3, and H4 (1013), or their unstructured N-terminal tail which are hotspots for PTMs (7). Amongst several 
PTMs, histone acetylation and methylation are stable epigenetic PTMs that occur on the basic (Lys/ Arg) N- terminal residues and are transmitted from parent to daughter cells during divisions $(7,14)$. Certain residues of the histone proteins are prone to methylation by histone methyltransferases (HMTs) and its counterpart, histone demethylases (HDMTs), leading to cooccurrence of acetylation and methylation (15). Histone acetylation modifications are governed by a balanced interplay between the catalytic enzymes, histone acetyltransferases (HATs) and histone deacetylases (HDACs) (16). While HATs are "writer" enzymes that yield open chromatin conformation by transferring an acetyl group to the NH2-terminal Lys residue on histone tail, HDACs are "eraser" enzymes that undo the result of HAT activity, yielding a closed repressive conformation of conformation of the chromatin structure (8). In humans, HATs can largely be divided into GCN5-related N-acetyltransferase (GNAT) comprising of GCN5 and PCAF), MYST including MOZ, MOF, TIP60, and HBO1, and p300/cAMP-responsive elementbinding protein (CBP) (17). Recognition of acetyl-Lys by HATs is facilitated by a conserved "reader' bromodomain (BRD) motif (18). Specific histone modifications occur at initial stages with their accretion during tumorigenesis, like genome-wide loss of H4K16ac and H4K20me3, regarding them as hallmarks of cancer $(11,12)$. Additionally, incidence of histone methylation at specific residues is a hallmark of various cancers, especially breast cancer (15).

The significance and reversibility of histone modifications makes them targetable by epigenetic therapies, such as treating with histone deacetylase inhibitors (HDACis), since they can reactivate the genes silenced due to deacetylation and chromatin condensation. HDACi also display antitumorigenic effects like cell cycle arrest, inhibiting cell growth, and induction of apoptosis $(19,20)$. Targeting breast cancer cells with HDACis is a therapeutic strategy more effective and efficient than targeting individual genetic pathways. Given the frequency, morbidity and mortality associated with breast cancer, the past decade has witnessed an incredible expansion of research into HDACis as a novel and promising approach. In addition to being used in monotherapy, studies have reported their exceptional efficacy when used in combination therapy with other treatment strategies (21). Although quite a few studies discuss their roles in other types of cancers, however, to the best of our knowledge, none have reviewed the advances in HDACis when it comes to breast cancers, individually. With the aim of setting the stage for discovery of new HDAC inhibitors for the treatment of breast cancer, this review provides insights into structural facets of targeting HDACs to facilitate rational structure-based drug discovery. The review also probes on differential expression of HDAC isoforms in breast cancer, emphasizing the need to promote isoform-selective HDAC inhibition by translating available structural knowledge to design selective and effective HDACi therapeutics against breast cancer.

\section{Classification of human HDACs}


Eighteen different HDACs have been identified in humans that are divided into four classes (Class I-IV), based on their homology with yeast proteins - reduced potassium dependency 3 (Rpd3), histone deacetylase-A 1 (Hda1) and silent information regulator 2 (Sir2) (22). Classes I, II, and IV are dependent on single transition $\mathrm{Zn}^{2+}$ metal ion, and class III is structurally and evolutionarily distinct with its activity characterized by nicotinamide adenine dinucleotide (NAD+) dependence (22). Each class represents HDACs with a common descendance having considerable sequence homology and comparable 3-D conformation yielding similar functions (23). Class I HDACs consist of HDAC1, HDAC2, HDAC3, and HDAC8 which are localized in the nucleus share 45\%-94\% identity in their amino acid residues (Fig. 1A). HDAC1-3 of this class are widely involved in formation of corepressor complexes with increased expression during several cancer types. While HDAC1 and HDAC2 interact to form CoREST, NuRD and Sin3A complexes, N-CoR complexes involve HDAC3 (23). The fourth member of this class, HDAC8, displays a truncated C-terminus and functions as a single polypeptide (24). Members of Class II are subdivided into class IIa encompassing HDAC4, HDAC5, HDAC7, and HDAC9, and class IIb including HDAC6 and HDAC10. While HDACs from class IIa are primarily localized in the cytoplasm, their phosphorylated state mediates their shuttling from the nucleus to the cytoplasm (25). Members of this class share specific features with conserved catalytic domains of Class I HDACs, along with an additional distinct domain. An extended C-terminal domain enhances the otherwise poor deacetylase activity by facilitating interactions with members of class I to form corepressor complexes. This can be exemplified by involvement of interaction between HDAC4 and HDAC3 to form the catalytic domain of NcoR-SMRT corepressor complex (26). Class IIa $\mathrm{N}$-terminus is responsible for translocation from nucleus to cytoplasm by promoting CaM kinase mediated phosphorylation of the repeating Ser residues and also holds interaction domains like the MEF2 domain (27). Moreover, HDAC4, HDAC5, HDAC7, and HDAC9 align with an overall identity of 48\%-57\% (23). Among the class IIb members, HDAC6 represents a unique protein relative to all other classes in the histone deacetylase family with two intact and functional catalytic domains, and a zinc finger ubiquitinbinding domain crucial for regulating aggresome formation and managing stress generated due to misfolding of proteins $(28,29)$. On the other hand, little is known about the second member of class IIb, HDAC10, apart from the missing duplicated catalytic domain found in HDAC6. This class of HDAC is localized predominantly to cytoplasm due to presence of nuclear export signal (NES) and Ser-Glu-containing tetrapeptide (SE14) motif responsible for its cytoplasmic anchoring (30). Alignment of conserved deacetylase domains of members of both class IIa and IIb yields a 23\%-81\% amino acid sequence identity (Fig.1A) (23). HDAC11 is the sole member of Class IV, which shares sequence similarities with both class I and class II HDACs (14). Again, HDAC11 presents a scenario similar to that of HDAC10, with little-to-no structurefunction information. Each HDAC contains at least one acetyl-lysine binding domain, however its localization is class-specific. To carry deacetylase activity on acetyl-lysine, catalytic loops L2 and L4 of zinc-dependent HDACs come in direct contact with the acetylated peptide, with reported crucial role of conserved Asp (except in HDAC11) in constraining the bound peptide in 
a cis-conformation by forming hydrogen bonds with backbone nitrogen atoms that flank the substrate lysine (Fig.2A) (31). It is worthy to note how a Tyr to His substitution in L4 of class IIa members (Fig. 1A \& 2A) results in a 1000-fold reduction in catalytic activity (32). Moreover, Ser39 of HDAC8 within $5 \AA$ Lys36 in L1 is a site for phosphorylation, responsible for reducing its deacetylase activity by destabilizing L1 (33).

The NAD+ - dependent class III HDACs (SIRT1-7) share 22\%-50\% identity in their overall amino acid residues and are phylogenetically apportioned into class I (SIRT1, SIRT2, SIRT3), class II (SIRT4), class III (SIRT5), and class IV (SIRT6, SIRT7), with their localization in nucleus, cytoplasm, and the mitochondria (34). In addition to deacetylating lysines on histone substrates, their activity spectrum includes non-histone substrates such as p53 tumor suppressor proteins (35), FOXO transcription factors (36, 37), $\alpha$-tubulin (38), PGC-1 $\alpha$ (39), acetyl-CoA synthetases (40-42), and glutamate dehydrogenase (43). Members of this class possess an additional mono-ADP-ribosyltransferase enzymatic domain in addition to the catalytic histone deacetylase domain, with SIRT5 demonstrating protein lysine desuccinylase and demalonylase activities (44). NAD+ drives the deacetylation of bound acetyl-lysine peptide, by occupying three binding regions, each for its adenine- ribose (Site A), nicotinamide- ribose (Site B), and the nicotinamide moiety (Site C) (45). A sequence-based alignment of HDACs and SIRTs exhibits the members of the families to share $21 \%-94 \%$ and $27 \%-88 \%$ identity in their conserved catalytic domains, respectively (23).

\section{Structural insights into HDAC classes}

Current search in the Protein Data Bank (PDB), a protein structure repository, yields more than 10,000 resolved structures of human HDACs either in ligand-bound/apo or mutated form. A consolidated list of relevant HDAC PDB structures from each class is tabulated for ready reference (Table 1). For comparative analysis of catalytic domains amongst different HDAC classes, 4BKX, 3C0Z, and 5EDU have been rationally selected (based on resolution and query sequence coverage) as representatives for classes I, IIa, and IIb, respectively (Fig. 2A). Similarly, 5BTR, 3RIG, and 3PKI are selected for showing phylogenetically distinguished SIRT classes I, III, and IV respectively (Fig. 2B). Missing crystal structures of HDAC11 and SIRT4 renders any discussion for class IV zinc-dependent HDACs and class II SIRTs unfeasible. 
Table 1: Protein Data Bank deposited structures of all HDAC classes.

\begin{tabular}{|c|c|c|c|c|c|c|c|}
\hline \multirow{2}{*}{$\begin{array}{l}\text { HDAC } \\
\text { (Size) }\end{array}$} & \multirow[t]{2}{*}{ Domain(s) } & \multirow{2}{*}{$\begin{array}{c}\text { PDB ID } \\
\text { (Resolution) }\end{array}$} & \multirow{2}{*}{$\begin{array}{c}\text { Chain(s) with } \\
\text { representative } \\
\text { domain (Chain } \\
\text { length) } \\
\end{array}$} & \multicolumn{2}{|c|}{ Ligand(s) } & \multirow{2}{*}{$\begin{array}{l}\text { Related } \\
\text { Structure } \\
\quad(\mathbf{s})\end{array}$} & \multirow[t]{2}{*}{ Reference (s) } \\
\hline & & & & $\begin{array}{c}\text { Protein ligands } \\
\text { (Chain(s) and length) }\end{array}$ & $\begin{array}{c}\text { Small molecule (in } \\
\text { Chain) }\end{array}$ & & \\
\hline \multicolumn{8}{|c|}{ CLASS I } \\
\hline \multirow[t]{3}{*}{$\begin{array}{l}\text { HDAC1 } \\
\text { (482aa) }\end{array}$} & \multirow[t]{3}{*}{$\begin{array}{l}\text { Histone } \\
\text { deacetylase }\end{array}$} & $\begin{array}{l}4 \mathrm{BKX} \\
(3.00 \AA)\end{array}$ & B (422 aa) & MTA-1 (A; 176 aa) & $\begin{array}{l}-\mathrm{SO} 4(\mathrm{~B}) \\
-\mathrm{ZN}(\mathrm{B}) \\
-\mathrm{ACT}(\mathrm{B}) \\
-\mathrm{K}(\mathrm{B}) \\
\end{array}$ & -- & (46)] \\
\hline & & $\begin{array}{l}6 \mathrm{Z} 2 \mathrm{~K} \\
(4.5 \AA)\end{array}$ & $\begin{array}{l}\text { C, E, I, K (482 } \\
\text { aa) }\end{array}$ & $\begin{array}{l}\text { - DNTTIP (A, B, G, } \\
\text { H; } 130 \text { aa) } \\
\text { - MiDAC (D, F, J, L; } \\
173 \text { aa) }\end{array}$ & $\begin{array}{l}\text { - IHP (D, E, F, J) } \\
\text { - ZN (C, E, I, K) } \\
\text { - K (C, E, I, K) }\end{array}$ & -- & (47)] \\
\hline & & $\begin{array}{l}5 \mathrm{ICN} \\
(3.3 \AA)\end{array}$ & B (376 aa) & $\begin{array}{l}\text { - MTA-1 (A; } 195 \text { aa) } \\
\text { - Novel peptide }(\mathrm{C} ; 9 \\
\text { aa) }\end{array}$ & $\begin{array}{l}\text { - IHP (A) } \\
- \text { ZN (B) } \\
- \text { K (B) }\end{array}$ & -- & (48) \\
\hline \multirow[t]{2}{*}{$\begin{array}{l}\text { HDAC2 } \\
(488 \mathrm{aa})\end{array}$} & \multirow[t]{2}{*}{$\begin{array}{l}\text { Histone } \\
\text { deacetylase }\end{array}$} & $\begin{array}{l}3 \mathrm{MAX} \\
(2.05 \AA)\end{array}$ & $\mathrm{A}, \mathrm{B}, \mathrm{C}(367 \mathrm{aa})$ & -- & $\begin{array}{l}\text { - LLX }(\mathrm{A}, \mathrm{B}, \mathrm{C}) \\
\text { - NHE (A) } \\
\text { - ZN }(\mathrm{A}, \mathrm{B}, \mathrm{C}) \\
\text { - CA }(\mathrm{A}, \mathrm{B}, \mathrm{C}) \\
\text { - NA }(\mathrm{A}, \mathrm{B}, \mathrm{C})\end{array}$ & -- & (50) \\
\hline & & $\begin{array}{l}5 \mathrm{IX} 0 \\
(1.72 \AA)\end{array}$ & A, B, C (369 aа) & -- & $\begin{array}{l}\text { - 6EZ (A, B, C) } \\
\text { - PG4 (A, C) } \\
\text { - PG5 (A, B) } \\
\text { - PGE }(\mathrm{A}, \mathrm{B}, \mathrm{C}) \\
\text { - PEG }(\mathrm{A}, \mathrm{B}, \mathrm{C})\end{array}$ & $5 \mathrm{IWG}$ & (51) \\
\hline
\end{tabular}




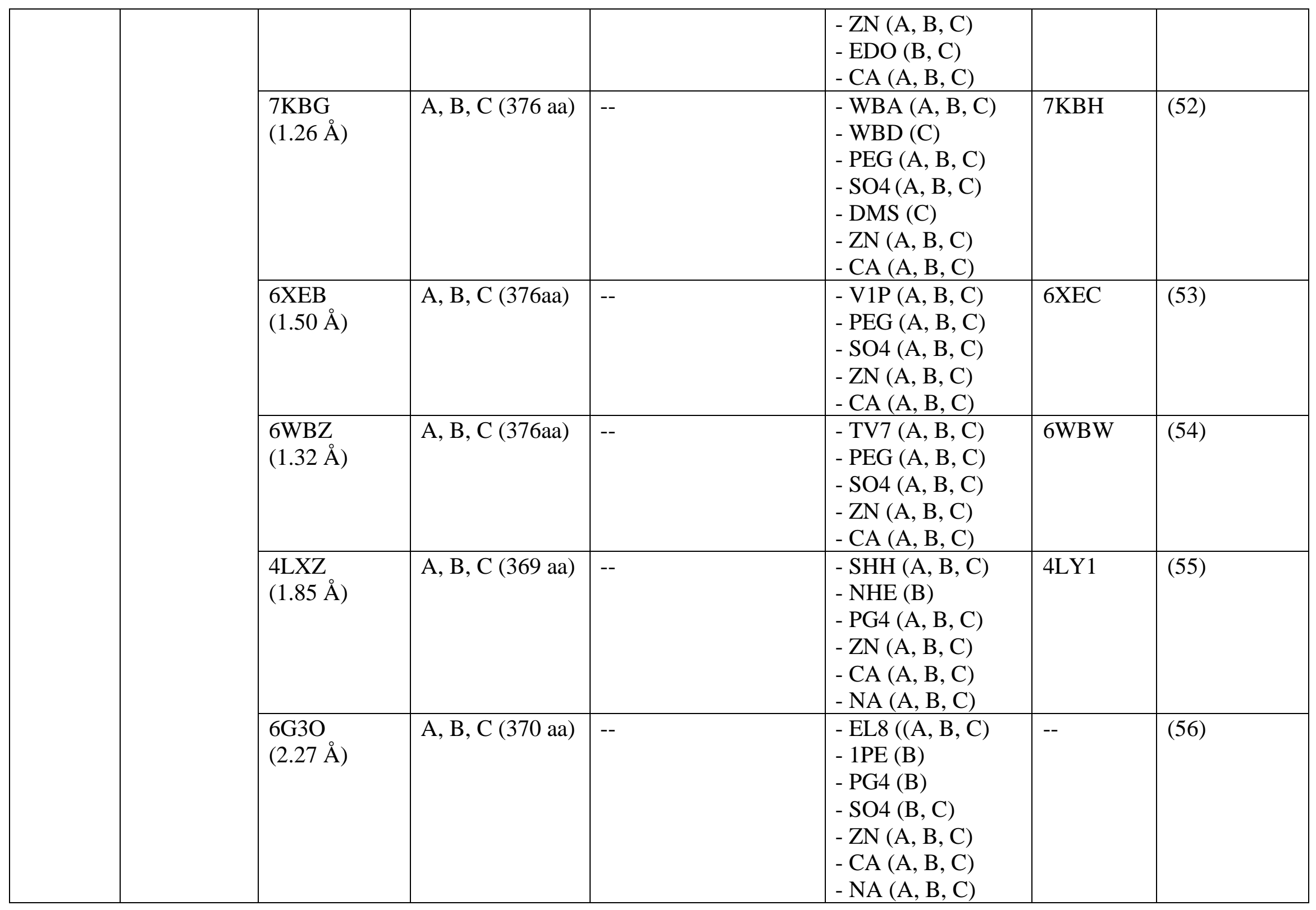




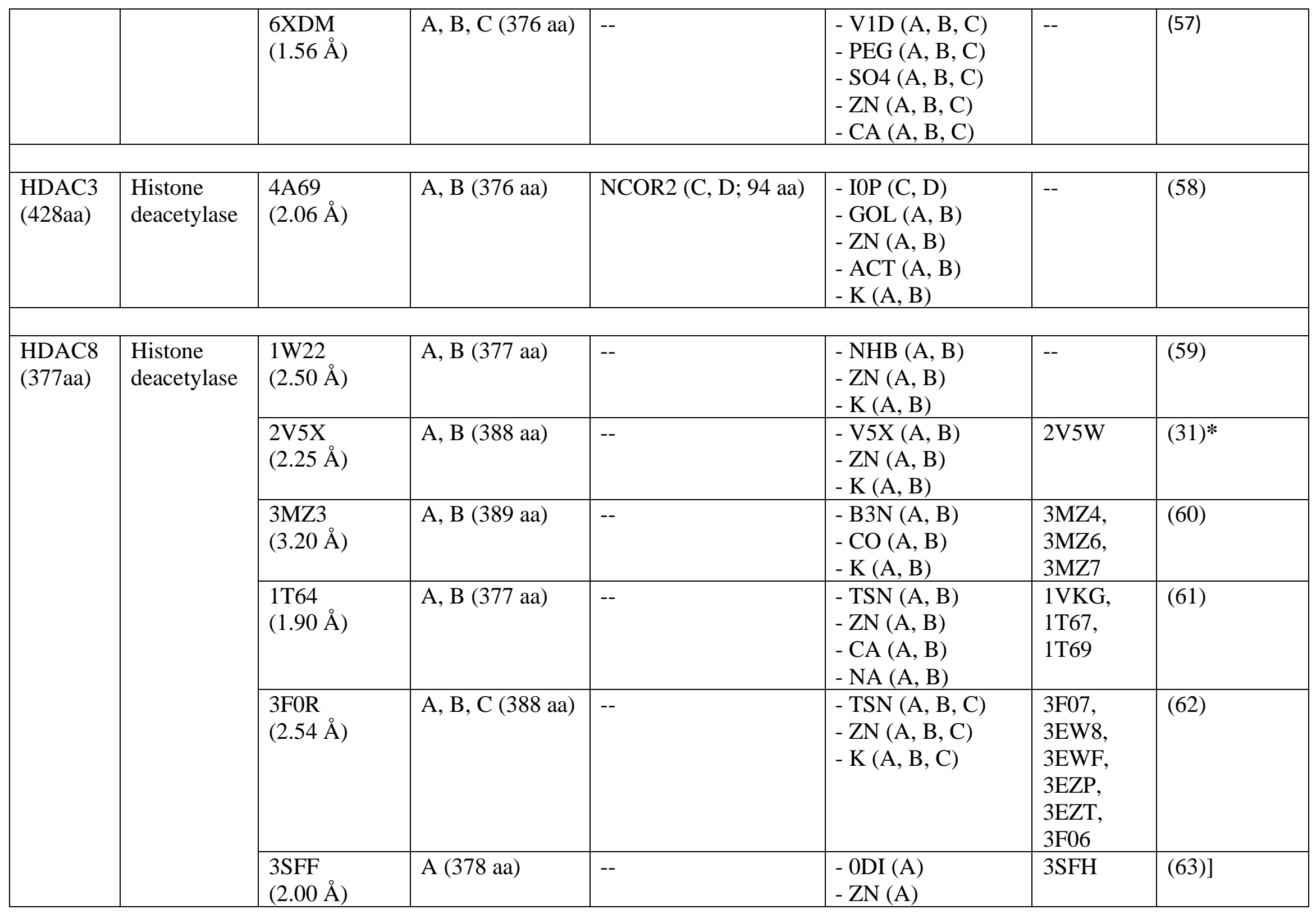




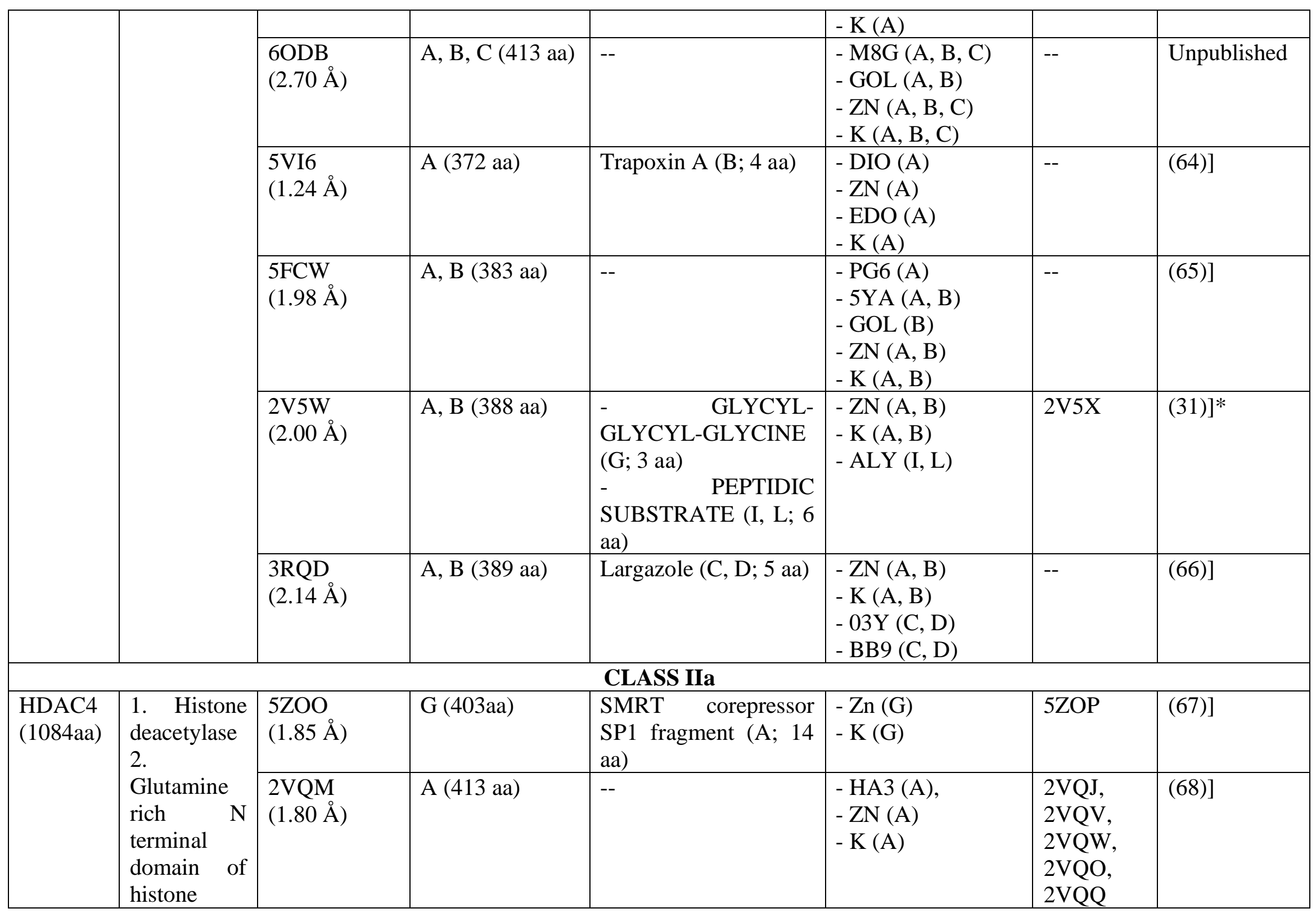




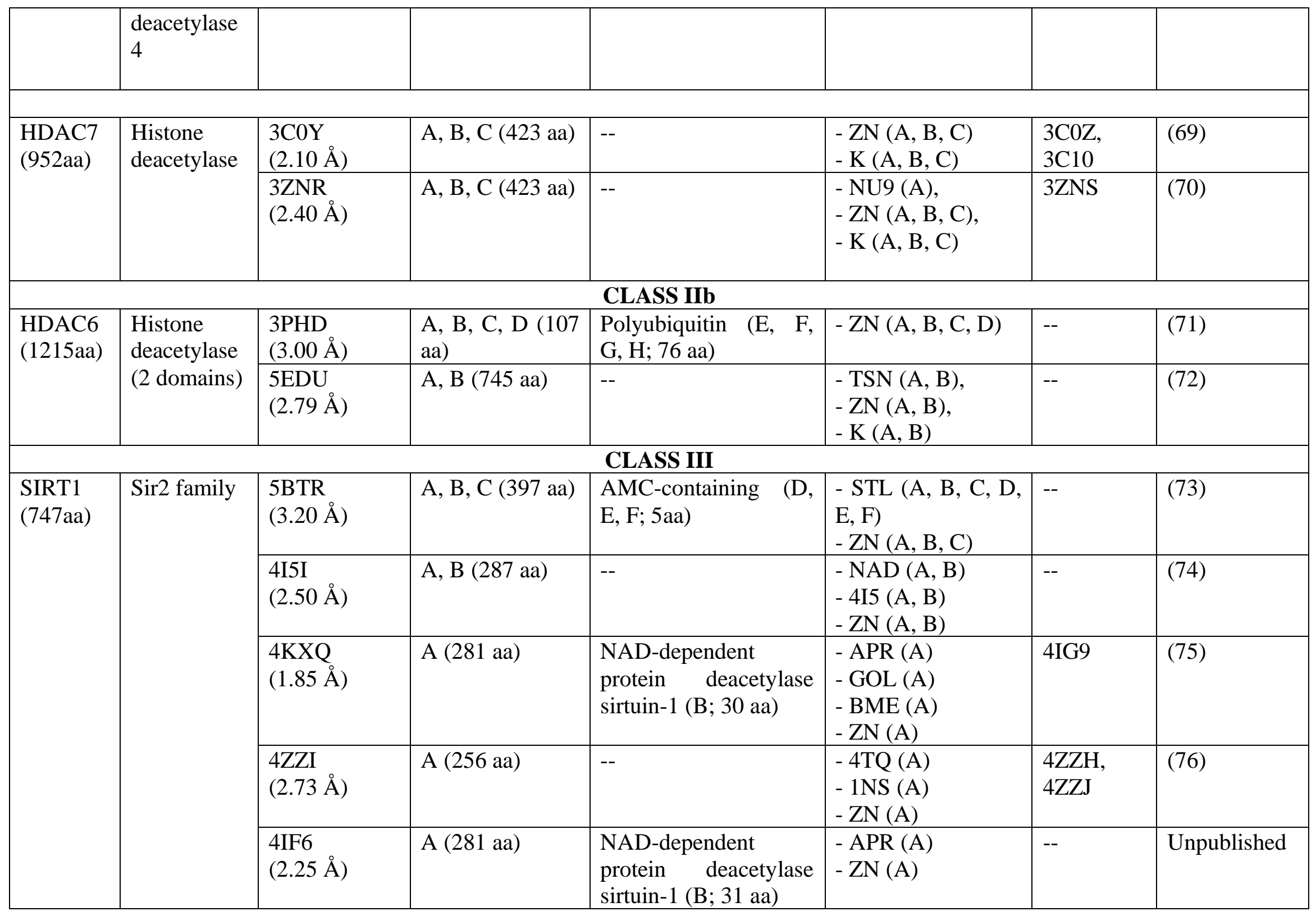




\begin{tabular}{|c|c|c|c|c|c|c|c|}
\hline \multirow[t]{8}{*}{$\begin{array}{l}\text { SIRT2 } \\
\text { (389aa) }\end{array}$} & \multirow[t]{8}{*}{ Sir2 family } & $\begin{array}{l}3 \mathrm{ZGO} \\
(1.63 \AA)\end{array}$ & $\mathrm{A}, \mathrm{B}, \mathrm{C}(325 \mathrm{aa})$ & -- & $\begin{array}{l}\text { - P6G (A) } \\
\text { - PGE (A, B, C) } \\
\text { - ZN (A, B, C) } \\
\text { - EDO (A) } \\
\text { - EOH (B) }\end{array}$ & $3 \mathrm{ZGV}$ & (77) \\
\hline & & $\begin{array}{l}\text { 4BVB } \\
(2.00 \AA)\end{array}$ & A (284 aa) & -- & $\begin{array}{l}\text { - AR6 (A) } \\
\text { - OCZ (A) } \\
\text { - ZN (A) }\end{array}$ & $\begin{array}{l}4 \mathrm{BVF}, \\
4 \mathrm{BV} 2 \\
4 \mathrm{BVE}, \\
4 \mathrm{BVG}, \\
4 \mathrm{BUZ}\end{array}$ & (78) \\
\hline & & $\begin{array}{l}4 \mathrm{X} 3 \mathrm{O} \\
(1.50 \AA)\end{array}$ & A (304 aa) & $\begin{array}{l}\text { peptide PRO-LYS- } \\
\text { LYS-THR-GLY (C; } 5 \\
\text { aa) }\end{array}$ & $\begin{array}{l}-3 \mathrm{YO}(\mathrm{C}) \\
-\mathrm{ZN}(\mathrm{A}) \\
-\mathrm{EDO}(\mathrm{A})\end{array}$ & -- & Unpublished \\
\hline & & $\begin{array}{l}4 \mathrm{Y} 6 \mathrm{~L} \\
(1.60 \AA)\end{array}$ & A, B (293 aa) & $\begin{array}{l}\text { peptide THR-ALA- } \\
\text { ARG-MYK-SER- } \\
\text { THR-GLY } \quad \text { (C, D; } 7 \\
\text { aa) }\end{array}$ & $\begin{array}{l}-\mathrm{ZN} \\
-\mathrm{MYK}\end{array}$ & $\begin{array}{l}\text { 4Y6OO, } \\
\text { 4Y6Q }\end{array}$ & (79) \\
\hline & & $\begin{array}{l}\text { 6QCN } \\
(1.84 \AA)\end{array}$ & A, B (302 aa) & -- & $\begin{array}{l}\text { - AR6 (A, B) } \\
\text { - QUE (A) } \\
\text { - PG4 (A) } \\
\text { - PGE (B) } \\
\text { - SO4 (A, B) } \\
\text { - ZN (A, B) } \\
\text { - EDO (A) }\end{array}$ & $\begin{array}{l}\text { 6QCE, } \\
\text { 6QCH, } \\
\text { 6QCJ, } \\
\text { 6QCN }\end{array}$ & (80) \\
\hline & & $\begin{array}{l}5 \mathrm{D} 7 \mathrm{O} \\
(1.63 \AA)\end{array}$ & A, B (310 aa) & -- & $\begin{array}{l}\text { - AR6 (A, B) } \\
\text { - PGE (B) } \\
\text { - ZN (A, B) }\end{array}$ & $\begin{array}{l}5 \mathrm{D} 7 \mathrm{Q}, \\
5 \mathrm{D} 7 \mathrm{P} \\
5 \mathrm{D} 7 \mathrm{~N}\end{array}$ & (81) \\
\hline & & $\begin{array}{l}5 \mathrm{YQO} \\
(1.48 \AA)\end{array}$ & A (306 aa) & -- & $\begin{array}{l}\text { - L5C (A) } \\
\text { - ZN (A) }\end{array}$ & $\begin{array}{l}5 \mathrm{YQL}, \\
5 \mathrm{YQN}, \\
5 \mathrm{YQM}\end{array}$ & (82) \\
\hline & & $\begin{array}{l}\text { 4RMH } \\
(1.42 \AA)\end{array}$ & A (304 aa) & $\begin{array}{l}\text { Ac-Lys-H3 peptide } \\
\text { (B; } 7 \text { aa) }\end{array}$ & $\begin{array}{l}-3 \mathrm{TE}(\mathrm{A}) \\
-\mathrm{ZN}(\mathrm{A})\end{array}$ & $\begin{array}{l}\text { 4RMG, } \\
\text { 4RMI, }\end{array}$ & (83) \\
\hline
\end{tabular}




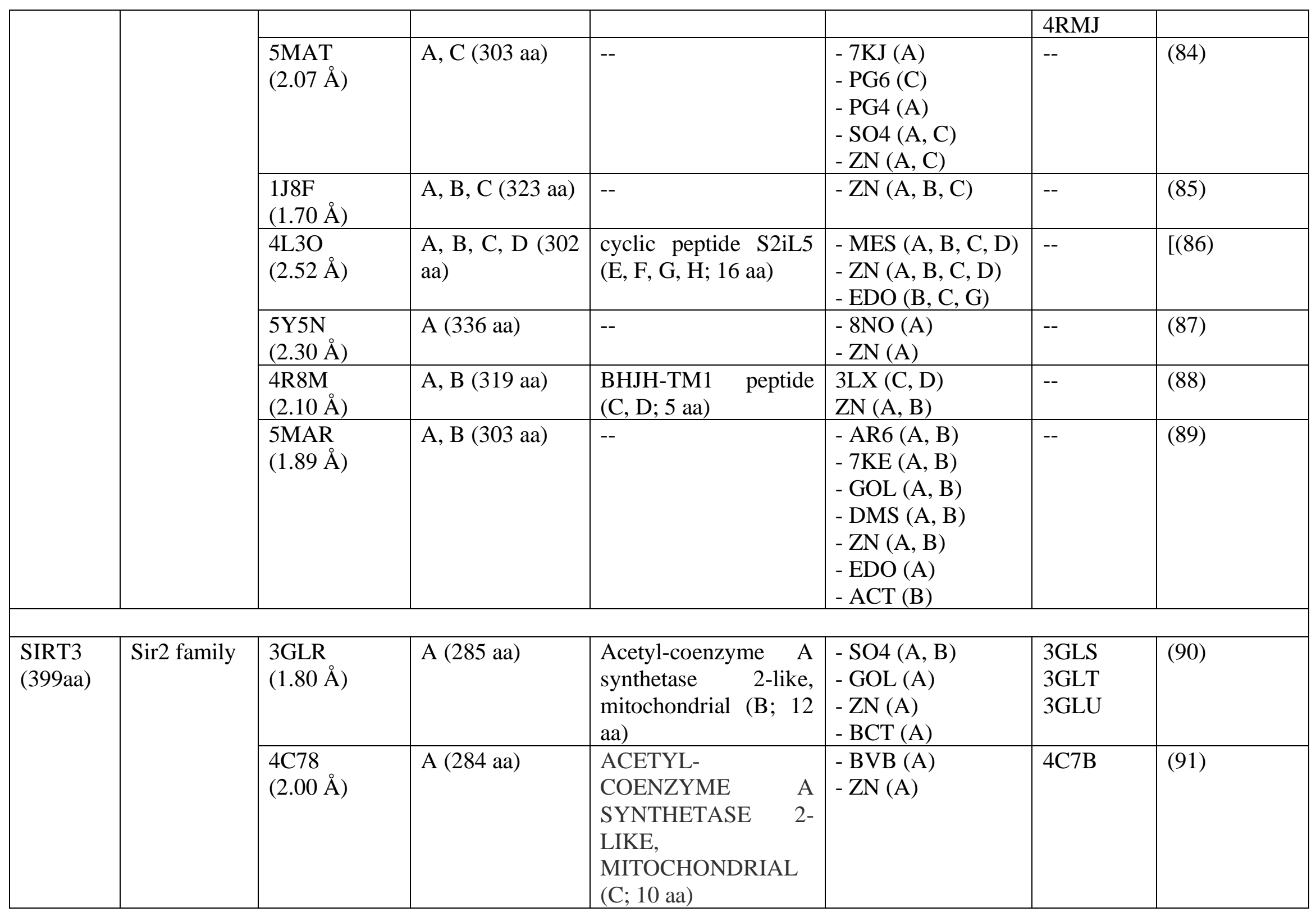




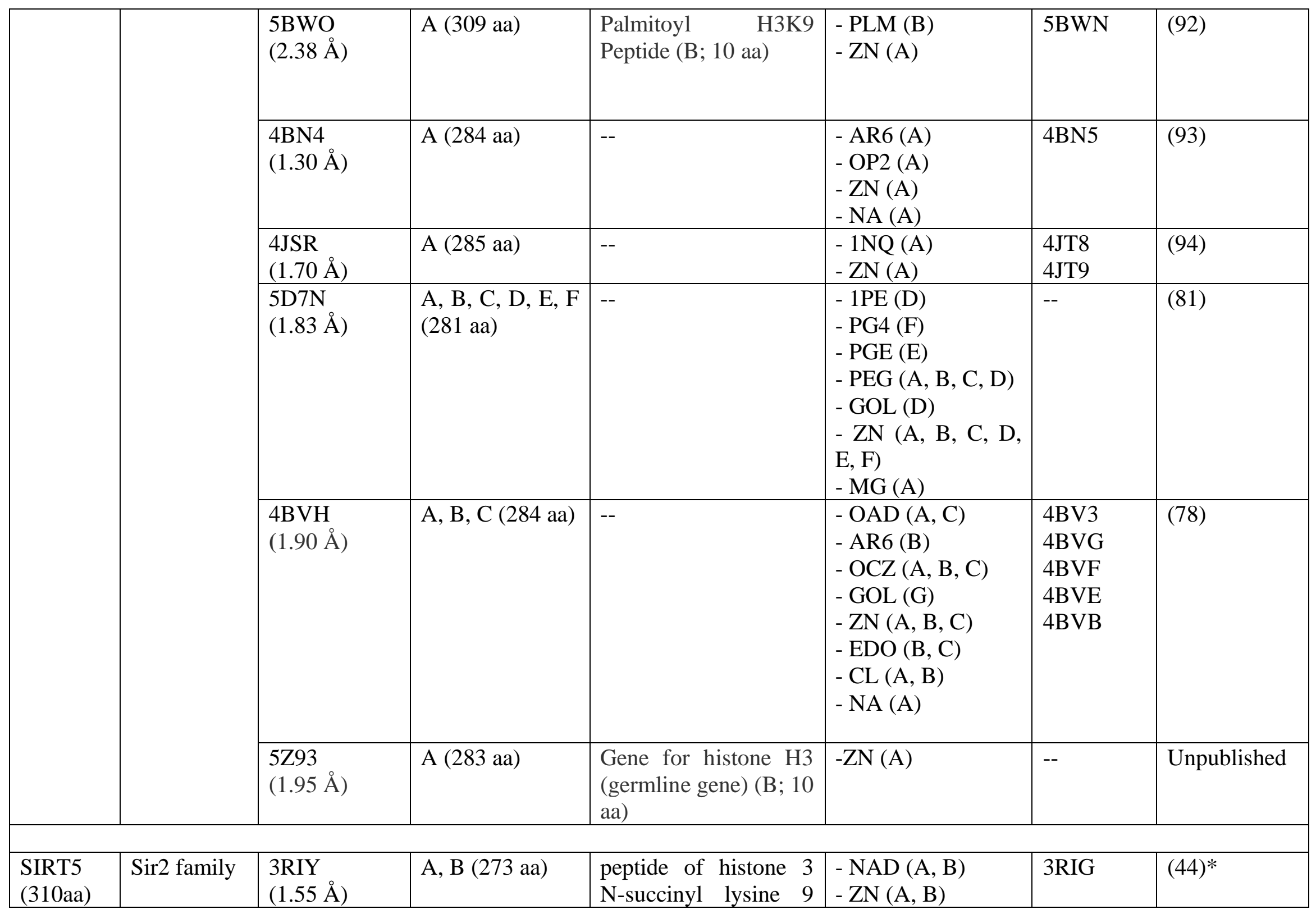




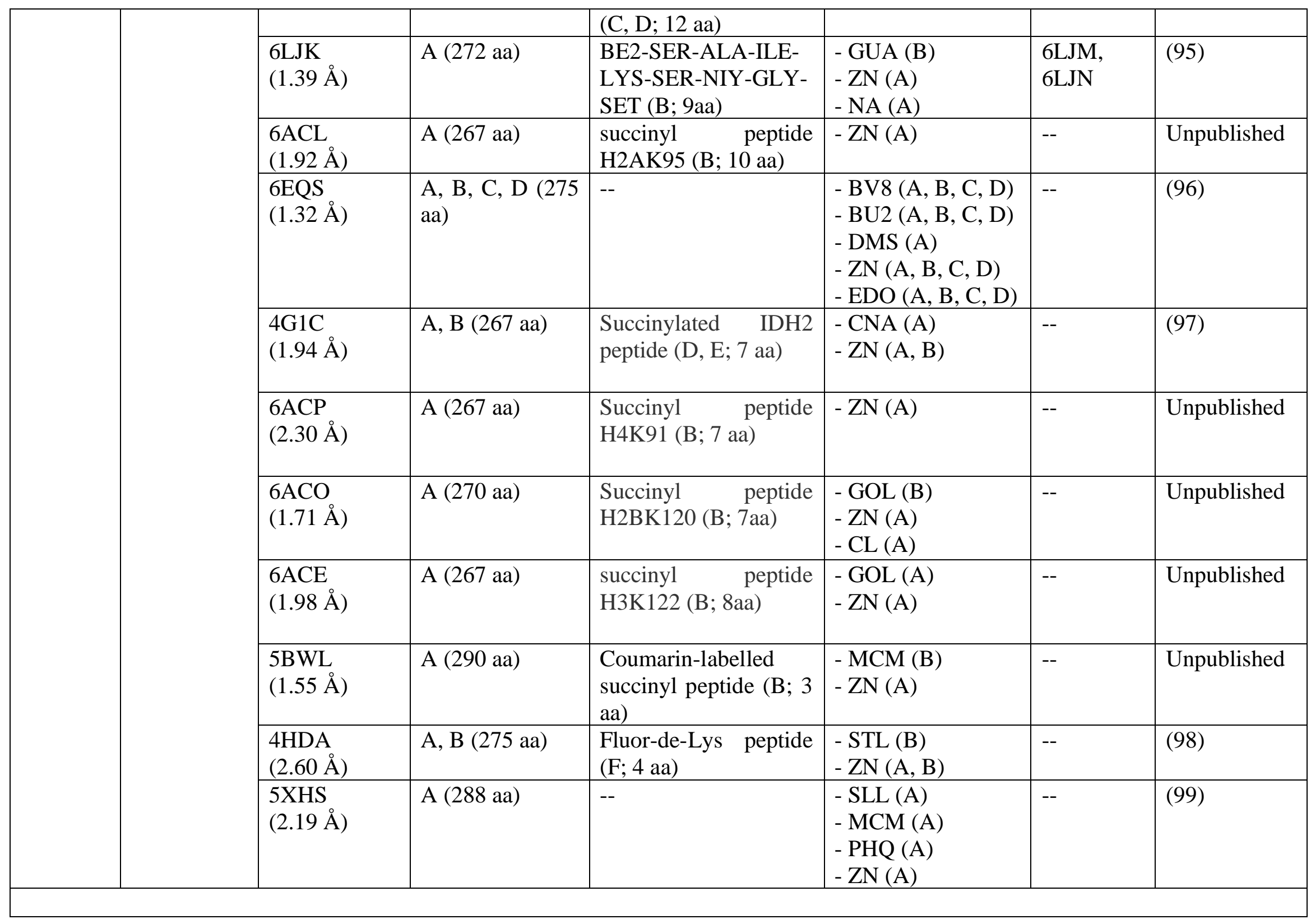




\begin{tabular}{|c|c|c|c|c|c|c|c|}
\hline \multirow[t]{6}{*}{$\begin{array}{l}\text { SIRT6 } \\
\text { (355aa) }\end{array}$} & \multirow[t]{6}{*}{ Sir2 family } & $\begin{array}{l}\text { 3PKI } \\
(2.04 \AA)\end{array}$ & $\begin{array}{l}\text { A, B, C, D, E, F } \\
(355 \text { aa) }\end{array}$ & -- & $\begin{array}{l}\text { - AR6 (A, B, C, D, } \\
\text { E, F) } \\
\text { - SO4 (A, B, C, D, } \\
\text { E, F) } \\
\text { - ZN (A, B, C, D, } \\
\text { E, F) } \\
\text { - UNX (A, B, C, D, } \\
\text { E, F) }\end{array}$ & $\begin{array}{l}3 \mathrm{~K} 35, \\
\text { 3PKJ }\end{array}$ & (100) \\
\hline & & $\begin{array}{l}\text { 6QCN } \\
(2.23 \AA)\end{array}$ & A, B (304 aa) & -- & $\begin{array}{l}\text { - AR6 (A, B) } \\
\text { - QUE (A) } \\
\text { - ZN (A, B) }\end{array}$ & $\begin{array}{l}\text { 6QCE, } \\
\text { 6QCD, } \\
\text { 6QCH, } \\
\text { 6QCJ }\end{array}$ & (80) \\
\hline & & $\begin{array}{l}5 \mathrm{MF6} \\
(1.87 \AA)\end{array}$ & A, B (302 aa) & -- & $\begin{array}{l}\text { - AR6 (A, B) } \\
\text { - 7M2 (A, B) } \\
\text { - PGE (A) } \\
\text { - SO4 (A, B) } \\
\text { - ZN (A, B) } \\
\text { - EDO (A, B) }\end{array}$ & $\begin{array}{l}\text { 5MGN, } \\
5 \mathrm{MFZ} \text {, } \\
5 \mathrm{MFP}\end{array}$ & (101) \\
\hline & & $\begin{array}{l}5 \mathrm{Y} 2 \mathrm{~F} \\
(2.53 \AA)\end{array}$ & A (316 aa) & $\begin{array}{l}\text { 9-mer peptide } \\
\text { QTARKSTGG (C;9 } \\
\text { aa) }\end{array}$ & $\begin{array}{l}\text { - 8L9 (A) } \\
\text { - AR6 (A) } \\
\text { - HDR (C) } \\
\text { - PEG (A) } \\
\text { - SO4 (A, C) } \\
\text { - GOL (A) } \\
\text { - ZN (A) }\end{array}$ & -- & (102) \\
\hline & & $\begin{array}{l}6 \mathrm{HOY} \\
(1.70 \AA)\end{array}$ & A, B (302 aa) & -- & $\begin{array}{l}\text { - AR6 (A, B) } \\
\text { - TSN (A, B) } \\
\text { - PG4 (A, B) } \\
\text { - SO4 (A, B) } \\
\text { - ZN (A, B) } \\
\text { - EDO (A, B) }\end{array}$ & -- & (103) \\
\hline & & $\begin{array}{l}6 \mathrm{XV1} \\
(1.95 \AA)\end{array}$ & A, B (302 aa) & -- & $\begin{array}{l}-8 \mathrm{~L} 9(\mathrm{~A}) \\
-\mathrm{AR6}(\mathrm{A}, \mathrm{B}) \\
\end{array}$ & -- & Unpublished \\
\hline
\end{tabular}




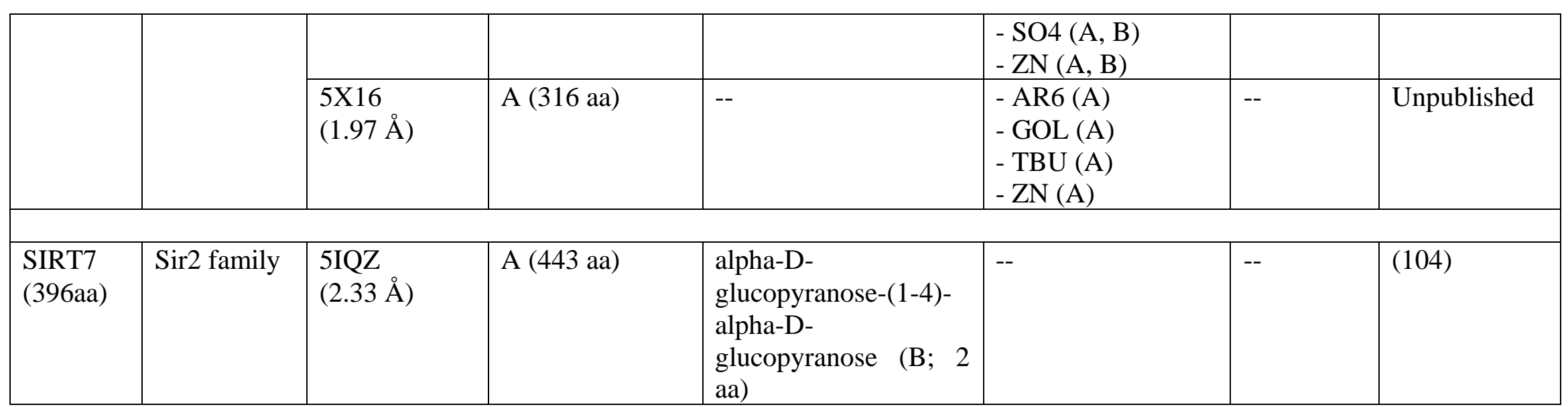

SO4: Sulfate ion; ZN: Zinc ion; ACT: Acetate ion; K: Potassium ion; IHP: Inositol hexakisphosphate; LLX: N-(4-aminobiphenyl-3yl)benzamide; NHE: 2-[N-cyclohexylamino]ethane sulfonic acid; CA: Calcium ion; NA: Sodium ion; 6EZ; (3-exo)-N-(4-amino-4'fluoro[1,1'-biphenyl]-3-yl)-8-oxabicyclo[3.2.1]octane-3-carboxamide; PG4: Tetraethylene glycol; PG5: 1-methoxy-2-[2-(2-methoxyethoxy]-ethane; PGE: Triethylene glycol; PEG: Di(hydroxyethyl)ether; EDO: 1,2-Ethanediol;WBA: N-\{(1S)-5-[(2-fluoro-6hydroxybenzene-1-carbonyl)amino]-1-[5-(naphthalen-2-yl)-1H-imidazol-2-yl]pentyl\}-1,3-thiazole-5-carboxamide; WBD: 2,5dichloro-1H-benzimidazole; DMS: Dimethyl sulfoxide; V1P: 5-\{(1S)-7,7-dihydroxy-1-[(1-methylazetidine-3-carbonyl)amino]nonyl $\}$ 2-phenyl-1H-imidazole-4-carboxamide; TV7: (1S)-N-\{(1S)-7,7-dihydroxy-1-[5-(2-methoxyquinolin-3-yl)-1H-imidazol-2-yl]nonyl $\}$ 6-ethyl-6-azaspiro[2.5] octane-1-carboxamide; SHH: SAHA; EL8: (6 \{R\})-6-[[3,4-bis(oxidanylidene)-2-[[4- (trifluoromethyloxy) phenyl]amino]cyclobuten-1-yl]amino]- \{N\}-oxidanyl-heptanamide; 1PE: Pentaethylene glycol; V1D: N-[(1S)-1-[4-(2-fluorophenyl)1H-imidazol-2-yl]-7,7-dihydroxy-7-(1,2-oxazol-3-yl)heptyl]-1-methylazetidine-3-carboxamide; I0P: D-myo inositol 1,4,5,6 tetrakisphosphate; GOL: Glycerol; NHB: N-hydroxy-4-(methyl\{[5-(2-pyridinyl)-2-thienyl]sulfonyl \}amino)benzamide; V5X: (2R)$\mathrm{N} \sim 8 \sim-h y d r o x y-2-\{[(5-m e t h o x y-2-m e t h y l-1 \mathrm{H}$-indol-3-yl)acetyl]amino $\}-\mathrm{N} \sim 1 \sim-[2-(2-$ phenyl-1H-indol-3-yl)ethyl]octanediamide; B3N: 4-(dimethylamino)-N-[7-(hydroxyamino)-7-oxoheptyl]benzamide; TSN: Trichostatin A; 0DI: (2R)-2-amino-3-(3-chlorophenyl)-1-[4(2,5-difluorobenzoyl)piperazin-1-yl]propan-1-one; MG8: N-octanoyl-N-methylglucamine; DIO: 1,4-diethylene dioxide; 5YA: 4naphthalen-1-yl- \{N\}-oxidanyl-benzamide; ALY: N(6)-acetyllysine; 03Y: 2-methyl-L-cysteine; HA3: N-hydroxy-5-[(3-phenyl-5,6dihydroimidazo[1,2-a]pyrazin-7(8H)-yl)carbonyl]thiophene-2-carboxamide; NU9: N-\{[4-(4-phenyl-1,3-thiazol-2-yl)tetrahydro-2Hpyran-4-yl]methyl\}-3-[5-(trifluoromethyl)-1,2,4-oxadiazol-3-yl]benzamide; STL: Resveratrol; NAD: Nicotinamide-AdenineDinucleotide; 4I5: (6S)-2-chloro-5,6,7,8,9,10-hexahydrocyclohepta[b]indole-6-carboxamide; APR: Adenosine-5-Diphosphoribose; BME: Beta-mercaptoethanol; $\quad$ 4TQ: (3S)-1,3-dimethyl-N-[3-(1,3-oxazol-5-yl)phenyl]-6-[3-(trifluoromethyl)phenyl]-2,3- 
dihydropyrido[2,3-b]pyrazine-4(1H)-carboxamide; 1NS: 1,2,3,4,5,6-hexahydroxy-cyclohexane ; P6G: hexaethylene glycol; EOH: Ethanol; OCZ: (1S)-6-chloro-2,3,4,9-tetrahydro-1H-carbazole-1- carboxamide ; 3Y0: [[(2R,3S,4R,5R)-5-(6-aminopurin-9-yl)-3,4bis(oxidanyl)oxolan-2-yl]methoxy-oxidanyl-phosphoryl] [(2R,3R,4R,5R)-3-oxidanyl-5-sulfanyl-4-tridecoxy-oxolan-2-yl]methyl

hydrogen phosphate; MYK: N6-myristoyl lysine ; QUE: Quercitin; L5C: N-[4-[[3-[2-(4,6-dimethylpyrimidin-2yl)sulfanylethanoylamino]phenyl]methoxy]phenyl]-1-methyl-pyrazole-4-carboxamide; $\quad 3 T E: \quad 2-[(4,6-$ dimethylpyrimidin-2yl)sulfanyl]-N-[5-(naphthalen-1-ylmethyl)-1,3-thiazol-2-yl]acetamide; 7KJ: (7 \{R\})-7-[(3,5-dimethyl-1,2-oxazol-4-yl)methylamino]3-[(4-methoxynaphthalen-1-yl)methyl]-5,6,7,8-tetrahydro-[1]benzothiolo[2,3-d]pyrimidin-4-one; $\quad$ MES: 2-(N-morpholino)ethanesulfonic acid; 8NO: 2-[[3-(2-phenylethoxy)phenyl]amino]benzamide; 7KE: 3-[3-(4-chlorophenyl)-1,2,4-oxadiazol-5yl]propan-1-ol; BCT: BICARBONATE ION; BVB: 5-[(E)-2-(4-bromophenyl)ethenyl]benzene-1,3-diol; PLM: Palmitic acid; OP2: 2[2-[2-[2-[2-(2-hydroxyethyloxy)ethoxy]ethoxy]ethoxy]ethoxy]ethanoic acid; 1NQ: N-\{2-[1-(6-carbamoylthieno[3,2-d]pyrimidin-4yl)piperidin-4-yl]ethyl\}-N'-ethylthiophene-2,5-dicarboxamide; 1PE: Pentaethylene glycol; MG: Magnesium ion; OAD: 2'-O-acetyl adenosine-5-diphosphoribose; OCZ: (1S)-6-chloro-2,3,4,9-tetrahydro-1H-carbazole-1- carboxamide; CL: Chloride ion; GUA: Glutaric acid; $\quad$ BV8: $\quad 3-[[(\sim\{\mathrm{Z}\})-\sim\{\mathrm{C}\}-[(2 \sim\{\mathrm{R}\}, 3 \sim\{\mathrm{R}\}, 4 \sim\{\mathrm{S}\}, 5 \sim\{\mathrm{R}\})-5-[[[[(2 \sim\{\mathrm{R}\}, 3 \sim\{\mathrm{S}\}, 4 \sim\{\mathrm{R}\}, 5 \sim\{\mathrm{R}\})-5-(6-$ aminopurin-9-yl)-3,4bis(oxidanyl)oxolan-2-yl]methoxy-oxidanyl-phosphoryl]oxy-oxidanyl-phosphoryl]oxymethyl]-3,4-bis(oxidanyl)oxolan-2-yl]sulfanyl$\sim\{\mathrm{N}\}-[(5 \sim\{\mathrm{S}\})-6-[[(2 \sim\{\mathrm{S}\})-3-(1 \sim\{\mathrm{H}\}$-indol-3-yl)-1-oxidanylidene-1-(propan-2-ylamino)propan-2-yl]amino]-6-oxidanylidene-5-

(phenylmethoxycarbonylamino)hexyl]carbonimidoyl]amino]propanoic acid; BU2: 1,3-BUTANEDIOL; CNA: carba-nicotinamideadenine-dinucleotide; MCM: 7-amino-4-methyl-chromen-2-one ; SLL: 6-N-succinyl-L-lysine ; PHQ: benzyl chlorocarbonate; UNX: unknown atom OR ION ; 7M2: (4 \{R\})-4-pyridin-3-yl-4,5-dihydropyrrolo[1,2-a]quinoxaline; 8L9: 5-[[3,5bis(chloranyl)phenyl]sulfonylamino]-2-[(5-bromanyl-4-fluoranyl-2-methyl-phenyl)sulfamoyl]benzoic acid ; HDR: Hexadecane-1sulfinic acid. 


\subsection{Catalytic fold of zinc-dependent HDACs}

The overall fold of zinc-dependent HDACs comprises of a single $\alpha / \beta$ domain made up of 8 stranded parallel $\beta$-sheet at the core surrounded by several $\alpha$-helices at the periphery, resulting in a tube-like cavity. In this pocket, the zinc ion is coordinated by polar catalytic residues His140, His141, Asp176, His178, Asp264, and Tyr303 (HDAC1 numbering, unless stated otherwise) (Fig. 1A). Mutagenesis studies have revealed the importance of His141 in catalyzing deacetylation, as H141A point mutation in HDAC1 drastically reduced deacetylase activity. This is also reinforced by site directed mutagenesis of equivalent H143A in HDAC8 that exhibit complete loss of activity $(62,105)$. Tyr303 is another catalytic residue with its hydroxyl group oriented inwards, facing the zinc ion that stabilizes the transient intermediate by forming hydrogen bonds. Substitution of this residue by His in Class IIa HDACs is known to reduce deacetylase activity, where the rotated side chain in outward orientation results in removal of a stabilizing force, thereby destabilizing transition state tetrahedral oxyanion (106). For HDACs to deacetylase its substrate, highly conserved hydrophobic residues Pro29, Gly149, Phe150, Phe205, and Lys271 bind to the acetyl-lysine's aliphatic arm (residues colored pink in Fig. 1A). The rim of the lysine channel is occupied by Asp99, a conserved residue in all zinc-dependent HDACs except for HDAC11, and helps in positioning the substrate entering the funnel. Incidentally, in a trifluoromethylketone (TFMK)-bound structure of HDAC4, it appears that the structurally equivalent Asp759 is located far away from the entrance to the lysine channel (107). This indicates the possibility of an allosteric mechanism of inhibition by TFMK, since this inhibitor does not occupy the catalytic site but leads to large differences in L1, L2 and Asp759 conformations. As mentioned above, HDAC6 harbours two catalytic domains CD1 and CD2 and mediates deacetylation activity mainly on cytoplasmic non-histone proteins such as tubulin, Hsp90, and cortactin, thereby regulating microtubule dynamics and chaperone activities (30). The tandemly organized domains are separated by a $\sim 24$ residue linker which interacts with Pro406 from CD1, and Arg642, Glu729, and Trp831 from CD2 (hHDAC6 numbering). Conserved His368 and His765 from CD1 and CD2, respectively stack on each other and are major contributors in stabilizing the interface (108). The two catalytic domains have differential substrate specificity as well as inhibitor selectivity. While CD2 displays stronger deacetylase activity and broad substrate specificity, CD1 has preference for acetyllysine substrates bearing a free $\alpha$-carboxylate group (108)[100]. A likely explanation is provided by the 3-D structure of zebrafish HDAC6 (zHDAC6) CD1-Trichostatin A (TSN) complex, where the inhibitor adopted different orientations in each of the active sites. The protruding side chain of zHDAC6 CD1 Lys330 (corresponding to Lys353 in human homolog), which is occupied by Leu712 in zebrafish CD2, is responsible for constricting the active site of CD1 (72). Comparative sequence analysis of these two domains from orthologous HDAC6 indicates Tyr225 and Phe105 as two additional amino acid substitutions in the hHDAC6 CD1 (Phe202 and His82 in zHDAC6 CD1) which further limits its active site. His82Phe and Phe202Tyr substitution mutations of zHDAC6 conferred significant specificity towards exo-acetyllysine group and abrogated binding to endo-acetyllysine group in peptide substrates. Thus, Tyr225 and 
Lys353 are involved in conferring specificity toward acetyllysine substrates bearing a free $\alpha$ carboxylate group (72). Another notable variation is the presence of a bulkier Trp282 in CD1 in place of Phe680 in CD2, which is involved in forming one wall of the hydrophobic channel where acetylated lysine binds (108). This imparts spatial restriction to allow selective entry of acetyllysine peptide substrates in CD1, rationalizing its narrowed specificity.

\subsection{Catalytic fold of NAD+- dependent SIRTS}

In case of NAD+-dependent class III SIRTs, all members share a $\sim 275$ residue long conserved catalytic core with flanking $\mathrm{N}$ - and $\mathrm{C}$ - termini. Isoform specific variability in sequence and length of these termini contribute to cellular localization, oligomerization, and autoregulation processes (109). The catalytic domain of SIRTs embody a NAD+ binding Rossmann-fold (magenta color in Fig. 2B), which branches out via four connecting loops, to a smaller yet structurally diverse zinc-binding domain (cyan color in Fig. 2B) and a helical segment of three to four helices (green color in Fig. 2B). This arrangement forms two clefts surrounding the Rossmann-fold, that serve as binding sites for acetylated peptide and NAD+ (Fig 1B). Distant from the active site, the zinc ion coordinated by conserved sequence motif (Cys- $\mathrm{X}_{2-4}-\mathrm{Cys}-\mathrm{X}_{15-40-}$ Cys- $\mathrm{X}_{2-4}$-Cys) does not directly participate in deacetylation. However, its importance lies in maintaining the structural integrity of the catalytic core by holding the three $\beta$-strands together, as confirmed by loss-of-function mutations (110). The classic pyridine dinucleotide binding Rossmann-fold comprises of several $\alpha$ helices that sandwich a central $\beta$ sheet consisting of six parallel $\beta$ strands. Gly261, Thr262, and Ser263 (SIRT2 numbering, unless indicated otherwise) from the Rossmann-fold interact with pyrophosphate group of bound NAD+'s adenine, and a conserved Asn287 (Fig. 1B] interacts with 2'- and/or 3'-OH of adenine ribose located in a partially hydrophobic pocket. It is interesting to note that NAD+ binds to the sirtuin protein family in an inverted position in comparison with other Rossmann-fold containing enzymes, with its adenine base and nicotinamide group binding to the $\mathrm{C}$-terminal and $\mathrm{N}$-terminal halves of the $\beta$ sheet, respectively (111). Nicotinamide ribose that occupies site B lies in close proximity to the acetyl-lysine-binding cavity, with NAD+'s hydroxyl hydrogen bonding with carbonyl oxygen of the former. The acetylated lysine of the substrate interacts with two flanking $\beta$ strands in the central $\beta$ sheet of the enzyme to form a ' $\beta$ staple' that makes several hydrogen bonds with the main chain. Nicotinamide located at site $\mathrm{C}$ in its active conformation, interacts with Gly-Ala-Gly motif and Ile93, Phe96, and Asn168 residues (45). Upon binding of the peptide, a conformational shift brings the larger and smaller domains closer, resulting in correctly positioned catalytic

residues to form the hydrophobic acetllysine-binding tunnel. The cofactor and substrate binding cleft are highly conserved, however, variation can be observed in the smaller domain, especially in the isoform specific loops on protein surface, away from the active site (45). For example, SIRT5 has an insertion in the metal-binding motif that results in an extended loop which blocks the furrow between its metal binding motif and the helical bundle region rationalizing its weak deacetylase activity (90). SIRT2 also has an insertion although in the large domain that 
comprises of a helix with hydrophobic residues (Phe296, Met299, Ile300 and Leu303) that in SIRT5 are reflected as a hydrophilic surface. Similarly, equivalent surface in SIRT3 is occupied by Trp353, all suggesting that these different surface features probably dictate substrate specificity and/or protein-protein interaction.

No significant conformational change is induced upon NAD+ binding, but the cofactor-binding loop which is otherwise unstructured gets ordered and adopts varying conformations upon entry of a ligand (86). While several residues from this flexible loop, like Ala85, Gly86, Asp95, and Phe96 (SIRT2 numbering), extensively interact with NAD+, positioning of Phe96 indicates conformation of NAD+ -bound or unbound site C. When NAD+ is bound and nicotinamide occupies the site $\mathrm{C}$, Phe96 is located $\sim 4 \AA$ away from binding site, and in an unbound state, Phe96 precludes NAD+ binding by occupying the site $C$. Thus, dynamic positioning of Phe96 in $\mathrm{NAD}+$ active site, and flexibility of the cofactor-binding loop are crucial determinants of catalysis (45). The presence of Tyr103 and Arg106 in SIRT5's catalytic domain provides a larger substrate-binding site, accepting larger acyl group on lysine residues and promoting above mentioned lysine desuccinylase and demalonylase activity in place of deacetylation (44). Weak deacetylation is also demonstrated by SIRT6 which has a wide zinc-binding domain and lacks the otherwise conserved helix bundle that links Rossmann-fold to the small domain. In addition, SIRT6 also lacks the unstructured cofactor binding loop which is replaced by a single helix that appears to be ordered in both apo and ligand-bound forms, implying reduced flexibility of the substrate-binding pocket (100). While no crystal structure of human SIRT4 is available till date, structural insights from Sirt4 Xenopus tropicalis homolog (xSirt4) reveal the structure of acyl binding site and a preference for dehydroxymethylglutarylation activity, similar to SIRT5. The structure identifies additional isoform specific access channel and SIRT4 loop that adopts

minimum two states in the solved structures. It is postulated that for productive NAD+ binding this loop will undergo conformational rearrangement in the acyl site, possibly induced by yet to be identified modulators (112).

\section{Rationally targeting HDACs in Breast Cancer Subtypes}

HDACs hold the ability to play dual role in carcinogenesis by mediating both, induction and repression of underlying genes (113). Abnormal expression of HDACs has been reported in several breast cancers. In vitro studies on invasive MDA-MB-231 breast cancer cells reveal significantly augmented expression of matrix metalloproteinase-9, attributed to increased levels of HDAC1, 6 and 8 (114). Multiple HDACs, particularly HDAC1 and HDAC3 are elevated in breast cancer cells and associate with transcription factors E2F1 and E2F4 to repress ARH1 tumor suppressor gene, characterizing $>70 \%$ breast and ovarian tumors $(113,115)$. Similarly, increased expression of HDAC6 is linked with metastatic potential of ER+ breast cancers and also as a predictive indicator of response to endocrine therapy (116). Additionally, HDACs have been reported to inhibit the expression of a family of GABARAPL1 autophagy genes in breast 
cancer cells, low expression of which has been correlated with poor prognosis, suggesting HDACis may be employed to modulate autophagy levels in breast cancer and improve prognosis (117). A balanced interplay between HATs and HDACs provides support to transcriptional competence during myogenesis and p53-dependent transcription, thus, any alteration is directly involved in promoting cancer (16). Vascular endothelial growth factor (VEGF) is a crucial angiogenic factor induced upon acetylation of $\mathrm{H} 3$ and $\mathrm{H} 4$ histone proteins after FOXM1 transcription factor binds to the VEGF promoter. However, HDAC2 and HDAC3 can be recruited at the promoter region by transcription factor KLF-4 to rapidly deacetylate acetylated residues, thereby inhibiting VEGF expression and repressing breast cancer promotion (118). An orchestrated alliance between histone deacetylation and DNA methylation by formation of corepressor complexes discussed above is involved in remodeling of the nucleosome to regulate gene expression (119). A multimolecular corepressor complex of HDAC1 and DNMT1 has been shown to epigenetically regulate ER expression in breast cancer cells (120). Epithelial to mesenchymal transition (EMT) involved in breast cancer tumorigenesis is induced via elevated PRMT7 expression levels which interacts with HDAC3 to increase H4R3me2, and decrease H3K4me3, H3ac, and H4ac (121). Another HDMT, histone-lysine-specific demethylase1 (LSD1) interacts with HDACs to regulate gene expression and promote growth of breast tumors (122). Owing to the virtual ubiquity of HDACs in mediating histone acetylation and methylation patterns by associating with multimolecular complexes, their inhibition using HDACi epigenetic therapy has experienced a booming interest to purpose it for treatment of breast cancers.

Due to complex roles of HDACs in promoting or suppressing tumor cell growth, it is important to identify tissue as well as cancer specific expression patterns of epigenetic modulators and cellular processes/pathways implicated. Several studies have highlighted differential expression of HDACs in terms of human breast cancer progression and advancement. Immunohistochemical staining and quantitative real time RT-PCR analysis of HDAC6 mRNA levels from 135 female patients diagnosed with ER+ invasive breast cancer revealed its significance in prognosis against endocrine treatment, with higher HDAC6 expression signifying better survival in breast cancer (116). Another study utilized immune-histochemistry tools to show differential expression of HDAC1, HDAC2 and HDAC 3 in breast cancer. In HR+ tumors, high expression of HDAC1 was observed while HER2 overexpressing tumors and positive lymph node metastasis exhibited higher expression of HDAC2. Further, in tumors negative for HR and in less differentiated tumors, higher expression of both HDAC2 and HDAC3 was seen (123). Lapierre et al. (2016) reported significantly elevated expression of class IIa HDAC9 in basal cells at both, transcriptional and protein level, as compared to luminal breast cancer cells, leading to increase in cell proliferation and decrease in programmed cell death. Further investigations have led to the identification of SOX9 as the target of HDAC9 in breast cells, with its molecular mechanism yet to be studied (124). An integrated genomic and transcriptomic approach implied to analyze 18 HDAC genes in $~ 3000$ breast cancers reported a notably higher mRNA expression of HDAC2, SIRT5, and SIRT7 in basal-like breast cancers when compared with other subtypes (luminal A, luminal B, HER2+, and normal-like). This finding was correlated with expression of genes 
involved in DNA-damage response pathway, especially RAD51 (125). The study also revealed SIRT7 to be the most commonly amplified/overexpressed and SIRT3 to be the most underexpressed HDAC amongst the breast cancer specimens in TCGA (The Cancer Genome Atlas), corroborating earlier studies on the tumor-promoting role of SIRT7 and suppressive role of SIRT3 in breast cancer $(126,127)$. HDAC11 was observed to be highly expressed in luminal subtype breast cancer cell lines that are characterized by expression of ER $\alpha$. On treating the luminal breast cancer cell line ZR75-1with tamoxifen, a specific ER modulator, the mRNA expression of HDAC11 was found to be reduced (125). However, how HDAC11 modulates luminal breast cancer is a topic of further investigations. Finally, an interplay between LSD1 and HDAC5 was uncovered in TNBC cells. Knockdown of a LSD1 resulted in lower mRNA levels of HDAC isozymes, and inversely depletion of HDAC5 expression gave rise to an accumulation of H3K4me2, a specific substrate of LSD1 (128). More such studies are needed to match the growing relevance of differential HDAC isoform expression in specific cancer types, to rationalize the development of effectively targeted therapy.

\section{Clinical translation of targeted HDACi therapy against Breast Cancer}

The significance of abnormal HDAC expression in dysregulated pathways that are involved in advancing tumor proliferation, invasion, migration, and angiogenesis in cancer is wellestablished (129). Present section discusses the clinical translation of structure-based knowledge in strategizing selective HDAC inhibitors against breast cancer. The available pharmacophore model for zinc-binding HDACs typically comprises of three primary features: (i) a zinc-binding group $(\mathrm{ZBG})$ that interacts with the bound metal ion and plays a crucial role in determining potency of inhibitors, (ii) a cap group usually with an aromatic character or heteroaromatic hydrophobic moiety that occupies the rim to reach the active site of the HDAC enzyme to mediate selectivity against HDAC isoforms, and (iii) a hydrophobic linker region that connects the ZBG to the cap group, allowing an inhibitor to lie in the formed tunnel-like channel (130). With deposition of new HDAC structures to the PDB and better insights into different isoforms, selective inhibitors that potentially discriminate between each isoform can be strategized. The 'foot' was an additional element selective to some HDACi that occupied the 'foot-pocket' in the enzyme, and was included in their existing pharmacophore model (50). Identification of a potent HDAC2 inhibitor containing a 'foot' moiety indicated the volitional nature of a capping moiety for as long as other elements suffice in terms of balancing interactions (50). Variations in chemical structure of the metal-binding moiety in HDACi lead to their classification into five major classes: hydroxamic acid derivatives, cyclic peptides, benzamides, short-chain fatty acids, and ketones. To date, Vorinostat (SAHA), Romidepsin (FK228), Panobinostat (LBH589), and Belinostat (PXD101) have been approved by the FDA to treat Cutaneous T-cell lymphoma (SAHA and Romidepsin), Multiple Myeloma, and Peripheral T-cell lymphoma, respectively. Of these, hydroxamates show more potency in terms of $\mathrm{IC}_{50}$ values when compared to benzamides or carboxylates due to better metal-binding affinity to coordinate the zinc ion in the active site 
(131-133). QSAR studies reveal the significance of modifying the chain length, and saturated or unsaturated hydrocarbons in the linker element to enhance inhibitory activity. Hydrophobic and bulky groups in cap element of HDACi augment inhibitor potency by binding to the surface region in HDAC enzymes (133).

While no HDACi have been approved to treat breast cancers, several drugs are in the pipeline to treat breast cancer either as monotherapy or in combination (Table 2). A major shortcoming in the translation of these HDACi is the associated dose-limiting toxicities, including serious cardiotoxicity in case of vorinostat $(134,135)$, which can be attributed to the broad-spectrum activity against HDAC isoforms. Several class I and class II specific new generation HDACi are presently in clinical trials for the treatment of different types of breast cancers, including romidepsin (136), tucidinostat (137), and entinostat (138). Results for clinical potential of Tucidinostat (CS055) and Entinostat (MS-275) when administered adjuvant to endocrine therapy to treat advanced hormone-receptor positive breast cancer gave former an edge over the latter in their phase-III clinical trials. While tucidinostat revealed significantly improved rates of progression-free survival (PFS) from a median of 3.8 months (placebo) to 7.4 months (with tucidinostat), investigation on overall survival (OS) is ongoing (137). On the other hand, administration of adjuvant entinostat yielded a PFS median of 3.3 months (entinostat) as compared to 3.1 months (placebo), and an OS of 23.4 months (entinostat) versus 21.7 months (placebo) in a randomized phase III trial (139). Despite both being benzamide HDACi differentially selective to class I HDACs 1,2 , and 3, the failure of entinostat's phase-III trial can be attributed to tucidinostat's ability to also inhibit class IIb isotype HDAC-10. In addition, tucidinostat deploys epigenetic modulation over tumor cells by archiving optimal blood concentration yielding an enhanced antitumor response (140). This provides evidence for the need for an HDACi to specifically inhibit HDAC-10 to enhance PFS and OS, a correlation previously conjected for other cancer types (141). Thus, advancing towards a newer generation of class- and isotype-specific HDACi is a promising strategy to yield greater therapeutic value. Selective involvement of HDAC isoforms in breast cancer has previously been established (142), thereby upholding the need to selectively promote expression of HDAC1, HDAC6 (143), HDAC11 (144), and SIRT3 (145) isoforms, and inhibit the expression of HDAC3 (146), HDAC8 (147), HDAC4 (148), HDAC5 (149), HDAC7 (150), HDAC9 (124), SIRT1 (151), SIRT2 (152), SIRT4 (153), SIRT5 (154), SIRT6 (155), and SIRT7 (156). This urges the need to investigate and meet optimal structural requirements for HDAC inhibition so as to improve potency and specificity to different isoforms of HDACs. 
Table 2: HDACi in clinical trials for treatment of breast cancer [133, 153].

\begin{tabular}{|c|c|c|c|c|c|}
\hline $\begin{array}{l}\text { HDAC } \\
\text { inhibitor }\end{array}$ & $\begin{array}{l}\text { Pharmacophore (Cap group boxed } \\
\text { in green, linker in red, zinc binding } \\
\text { domain in blue) }\end{array}$ & $\begin{array}{l}\text { HDAC } \\
\text { Specificity } \\
\text { (Active site } \\
\text { residues) }\end{array}$ & Classification & $\begin{array}{l}\text { Clinical Trial } \\
\text { (Condition) }\end{array}$ & $\begin{array}{l}\text { Combination } \\
\text { Therapy }\end{array}$ \\
\hline $\begin{array}{l}\text { Vorinostat } \\
\text { (SAHA) }\end{array}$ & & $\begin{array}{l}\text { Class I, II, and } \\
\text { IV }\end{array}$ & $\begin{array}{l}\text { Hydroxamic } \\
\text { Acid }\end{array}$ & $\begin{array}{l}\text { Phase I/ II } \\
\text { (Metastatic BC) } \\
\text { Phase I (TNBC) } \\
\text { Phase II (Advanced } \\
\text { BC) } \\
\text { Phase II (ER+ Stage } \\
\text { IV BC) }\end{array}$ & $\begin{array}{l}\text { Olaparib, } \\
\text { Tamoxifen, } \\
\text { Ixabepilone, } \\
\text { Paclitaxel, } \\
\text { Bevacizumab }\end{array}$ \\
\hline Panobinostat & & Class I and II & $\begin{array}{l}\text { Hydroxamic } \\
\text { Acid }\end{array}$ & $\begin{array}{l}\text { Phase I/II } \\
\text { (Metastatic BC) } \\
\text { Phase II (HER } 2 \\
\text { locally recurrent or } \\
\text { metastatic BC) } \\
\text { Phase I (HER2 + } \\
\text { metastatic BC) } \\
\text { Phase I } \\
\text { Phase I (TNBC) }\end{array}$ & $\begin{array}{l}\text { Letrozole, } \\
\text { Trastuzumab, } \\
\text { paclitaxel } \\
\text { Capecitabine, } \\
\text { Lapatinib }\end{array}$ \\
\hline
\end{tabular}




\begin{tabular}{|l|l|l|l|l|}
\hline Valproic acid & $\begin{array}{l}\text { Short-Chain } \\
\text { Fatty Acid }\end{array}$ & $\begin{array}{l}\text { Phase I (Advanced } \\
\text { BC) }\end{array}$ & $\begin{array}{l}\text { Bevacizumab, } \\
\text { Cetuximab }\end{array}$ \\
\hline Phenylbutyrate & Class I and II & $\begin{array}{l}\text { Short-Chain } \\
\text { Fatty Acid }\end{array}$ & $\begin{array}{l}\text { Phase II } \\
\text { (Precancerous } \\
\text { breast cancer } \\
\text { conditions) }\end{array}$ \\
\hline Entinostat & Class I & $\begin{array}{l}\text { Benzamide } \\
\text { Early Phase I } \\
\text { (TNBC) } \\
\text { Phase I (Locally } \\
\text { recurrent or } \\
\text { metastatic BC) } \\
\text { Phase I/II/III } \\
\text { (Advanced BC) } \\
\text { Phase I (HER2- } \\
\text { BC) } \\
\text { Phase II (HR+, } \\
\text { HER2- BC) }\end{array}$ & $\begin{array}{l}\text { Exemestane, } \\
\text { Lapatinib } \\
\text { Ditosylate, } \\
\text { Azacitidine, } \\
\text { Ipilimumab, } \\
\text { Nivolumab }\end{array}$ \\
\hline
\end{tabular}




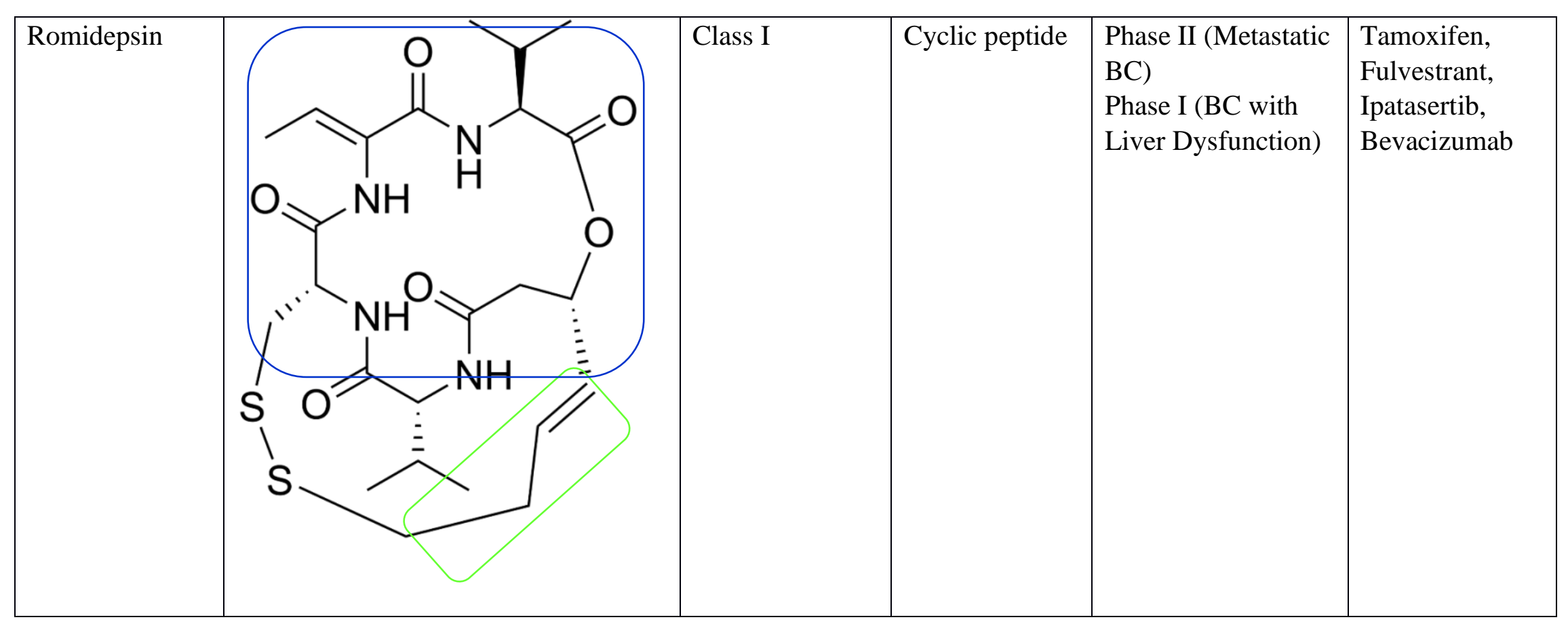




\subsection{Class I selective HDACi}

As previously described, members of class I share structural similarities in their catalytic domains, with HDAC8 being an exception. Alignment of HDAC1, 2, and 3 revealed differences in residues which can be exploited to further selective inhibition of HDAC3. An insertion of Phe199 in HDAC3 alters the orientation of neighboring Tyr198, facilitating the binding of selective inhibitors. Moving down to the foot pocket, replacement of HDAC1/2 Ser107 by Tyr107 in HDAC3 sterically hinders the binding of inhibitors due to Tyr's bulky R group, narrowing selectivity towards inhibitors with smaller functional groups. Deeper in the foot pocket, minor structural variations in residues 29 (Leu; HDAC3) and 13 (Val; HDAC3) can be exploited to enhance binding efficacy for HDAC3 (157). Selectivity of inhibitors with orthoaminoanilide scaffold which are otherwise selective for HDAC1-3, can be tapered against just HDAC3 by substituting different functional groups to the pharmacophore elements (157). In the same class, HDAC8 shares least homology in the catalytic domain compared to other isoforms. For selective inhibition of HDAC8, shorter catalytic loops L1 and L2, and the presence of some non-conserved residues (Pro273, Met274, Cys275, and Ser276) in L4 are promising distinguishing features that can be exploited (158). Another variation is the presence of a Trp141 (Fig. 2A) in place of conserved class I Leu139 (HDAC1 numbering) close to the active site. This substitution yields reduced potency of $o$-aminoanilide in inhibiting HDAC8 due to bulky nature of Trp which alters the active site geometry, preventing effective inhibitor binding (59). Marek et al. (2018) suggested a unique L-shaped conformation of the HDAC8-selective inhibitors which allows for them to bind to HDAC8 pocket formed by L1, L4, and catalytic Tyr, which is otherwise sterically locked to accommodate L-shaped inhibitors in HDAC1-3 isoforms (158). Reports have indicated the significance of inhibitors with relatively bulky heteroaryl cap group and an aromatic linker for enhanced inhibition of HDAC8 (159). Incorporation of $o$-benzyl group to ZBG improved HDAC8 selectivity and potency most likely by occupying a secondary hydrophobic surface pocket and making more interactions with the enzyme's active site (160).

\subsection{Class IIa selective HDACi}

Augmented expression of HDAC4, HDAC5, HDAC7, and HDAC9 in breast cancer cells calls for pan inhibition of Class IIa members. Compared to other classes, the catalytic domain of these HDACs bares distinguishing features which promote their selective inhibition. The previously discussed Tyr to His mutation in all members of this class results in a larger active site due to flipped geometry of His, which is otherwise occupied by Tyr in other classes. A second zinc binding domain that coordinates another $\mathrm{Zn}^{2+}$-ion to stabilize the protein structure is marked by an insertion of nearly 20 residues that form a helix-turn-helix- $\beta$-hairpin motif (L2), with the $\beta$ hairpin's tip involved in metal coordination (148). A conserved hydrophobic patch in L2 of HDAC4 and HDAC7, with some residues conserved in HDAC5 and HDAC9 can be a suitable target for the design of class IIa selective inhibitors (161). For class IIa selective inhibition, a 
group targeted the class-exclusive Tyr to His substitution and reported enhanced selectivity of HDACis containing trifluoromethyloxadiazole (TMFO) as a nonchelating ZBG, while adopting a U-shape in the active site (70). The larger active site in class IIa members facilitates accommodation of bulkier inhibitors as opposed to other classes, for which TMFO is a promising candidate that fits well to carry its catalytic activity. Regardless of their weak electrostatic interactions in the active site, TMFOs demonstrated potency and selectivity towards class IIa, due to improved cap group and linker region of the HDACi (70). This brings to light the potential of focusing on cap and linker regions instead of metal-chelating warhead for selective inhibition.

However, structural comparison reveals some features that can be exploited to inhibit specific members within class IIa. Insights into the conserved hydrophobic patch between HDAC4 and HDAC7 revealed different orientations of the patch. Residues Trp762, Glu764, and Arg730 of HDAC4 form a hydrogen bond and salt bridge network with Phe746 to yield a closed conformation. Conversely, corresponding residues (Trp629, Glu631, and Arg596) in HDAC7

point outwards, thereby rearranging the loop to push Arg596 away from Glu631, and provide an open conformation of the hydrophobic patch (161). This critical variation is a potential lead to strategize inhibitors that distinguish amongst class IIa isoforms. Positioning of hydrated trifluoromethyl ketone (TMFK) in place of hydroxamic acid increased the potency of binding of the HDACi to HDAC4 by about three times, while demonstrating better selectivity against other class IIa compared to class I members (68).

\subsection{Class III selective HDACi}

While preventing deacetylation of histone substrates in cancers is the prime reason of discovering inhibitors against class I, II, and IV HDACs, the focus in case of SIRTs is on nonhistone substrates, and their extensive roles in regulating metabolism and health (162). Additionally, a $\sim 260$ amino acid catalytic domain in SIRTs is conserved across prokaryotes and eukaryotes, poses a major challenge in synthesizing isoform-selective SIRT inhibitors (34). Nevertheless, recent advancements in medicinal chemistry with some support from insights into structural features $(163,164)$ have pushed the development of dual SIRT1/SIRT2, and SIRT3 selective inhibitors (165). A $\sim 20$ residue "C-terminal regulatory" (CTR) in SIRT1 was shown to form a $\beta$-hairpin with extended $\beta$-sheet of the catalytic domain, which can be an effective target to potentiate selectivity towards SIRT1 (75). A SIRT1 selective Ex-527-related inhibitor binds to the catalytic Rossmann-fold (74). Owing to the need of isoform-selective upregulation of certain SIRTS (like, SIRT3 in breast cancer), a newer strategy of "activating" specific isoforms by using Sirtuin-activating compounds (STACs) is nascent yet promising (164). However, no published studies indicate any SIRT3 selective STACs, augmented expression of which has been shown to be involved in improved outcome in breast cancer (145). While structural basis for isoform selectivity is yet to be fully explored, few NAD+ selective inhibitors like EX527, sirtinol, and 
saleramide were reported to induce breast cancer cell death in vitro by p53-acetylation via SIRT1/SIRT2 dual inhibition (166). Another inhibitor, splitomicin, and its derivatives, promoted tubular hyperacetylation and demonstrated anti-proliferative properties of MCF-7 breast cancer cell lines (167).

\section{Conclusion \& Perspective}

HDAC inhibitors justify the therapeutic potential of targeting reversible epigenetic modifications to normalize dysregulated gene expression in cancers. Clinically relevant FDA-approved inhibitors, Vorinostat, Romidepsin, Panobinostat, and Belinostat, mark the first success of an epigenetic therapy against cancer. Apart from monotherapy, their trials are also suggestive of their significance in combination therapy with existing therapies like administration of cytotoxic molecules, aromatase inhibitors, pro-drugs, and chemotherapy, primarily to improve their efficacy against solid tumors (Reviewed in (21)). Despite years of continuous efforts in analyzing structure-function of HDACs to discover improved new chemical entities, and having several HDACi in clinical trials, success is limited owing to the non-specificity of these inhibitors. Therefore, need of the hour is to develop target specific HDACis that might be more effective and less toxic. Studies to develop isoform selective HDACi are ongoing as we speak, by exploiting the faculty of available structural information in the Protein Data Bank. These structures include protein-ligand complexes, knowledge of which can be utilized to understand their interactions to design selective and potent HDACi. The ongoing research is also focusing on identifying allosteric inhibitors in place of active site inhibitors that exhibit low selectivity or disrupting protein-protein interactions $(50,58)$. In this context resolving 3-D structures of HDAC members HDAC5, HDAC9, HDAC10, HDAC11, and SIRT4 in apo or effector bound forms will be of significant value given their potential therapeutic applications. The flexibility in noncatalytic structural domains provides scope for easy tuning of HDACis with other pharmacophore elements to generate a 'hybrid HDACi' that represents multiple therapeutic activities (168). Several of these have been reported to be potential therapeutics against breast cancer treatment as well (169-171). These initiatives promote the much-needed addition of novel therapeutics to the pipeline against breast cancers, as no present strategies are efficient in treatment of TNBC, and no HDACi have yet been approved by the FDA either.

Further, the limitation of current HDACi also roots in their varying expression in different types of cancers. As tumor suppressor role of HDACs in some cases gets recognized, it is apparent that these should not be given carte blanche. For example, HDAC6 is a privileged target that is ubiquitously targeted by majority $\mathrm{HDACi}$, as it was reported to be associated with different expression in several disorders, including cancers (172). However, in breast cancers, HDAC6 overexpression was reported to be involved in better survival (116), partly justifying the shortcomings of approved HDACi limiting their purposing towards breast cancer. Breast cancer is a complex disease differing in clinical outcomes. Changes due to HDACs deregulation at the 
genomic, transcriptomic and proteomic levels and their clinical significance for most breast cancer subtypes are not known. It is imperative to identify differentially expressed HDACs in a specific subtype or tissue through fast multi-omics technologies and evaluate multiple parameters in the biopsy tissue /cell-free DNA. This will enable clinicians adopt personalized medicine approach of rationally targeting HDACs for good prognosis.

\section{Consent for Publication}

Declared none.

\section{Funding}

None.

\section{Conflicts of Interest}

The authors have no conflicts of interest to declare.

\section{Acknowledgements}

DM and VG would like to acknowledge Monika Antil for helping in preparing figures, and Juhi Mathur for her contribution in preparing Table 1. 


\section{References:}

1. Ferlay J, Colombet M, Soerjomataram I, Mathers C, Parkin DM, Pineros M, et al. Estimating the global cancer incidence and mortality in 2018: GLOBOCAN sources and methods. International journal of cancer. 2019;144(8):1941-53.

2. Ghoncheh M, Pournamdar Z, Salehiniya H. Incidence and Mortality and Epidemiology of Breast Cancer in the World. Asian Pacific journal of cancer prevention : APJCP. 2016;17(S3):43-6.

3. Turashvili G, Brogi E. Tumor Heterogeneity in Breast Cancer. Frontiers in medicine. 2017;4:227.

4. Sher G, Salman NA, Khan AQ, Prabhu KS, Raza A, Kulinski M, et al. Epigenetic and breast cancer therapy: Promising diagnostic and therapeutic applications. Seminars in cancer biology. 2020.

5. Institute NC. Hormone Therapy for Breast Cancer cancer.gov: National Institutes of Health; 2021. Available from: https://www.cancer.gov/types/breast/breast-hormone-therapy-fact-sheet.

6. Housman G, Byler S, Heerboth S, Lapinska K, Longacre M, Snyder N, et al. Drug resistance in cancer: an overview. Cancers. 2014;6(3):1769-92.

7. Cheng Y, He C, Wang M, Ma X, Mo F, Yang S, et al. Targeting epigenetic regulators for cancer therapy: mechanisms and advances in clinical trials. Signal transduction and targeted therapy. 2019;4:62.

8. Lustberg $M B$, Ramaswamy B. Epigenetic targeting in breast cancer: therapeutic impact and future direction. Drug news \& perspectives. 2009;22(7):369-81.

9. Yan PS, Perry MR, Laux DE, Asare AL, Caldwell CW, Huang TH. CpG island arrays: an application toward deciphering epigenetic signatures of breast cancer. Clinical cancer research : an official journal of the American Association for Cancer Research. 2000;6(4):1432-8.

10. $\mathrm{Xu} \mathrm{F,} \mathrm{Zhang} \mathrm{K,} \mathrm{Grunstein} \mathrm{M.} \mathrm{Acetylation} \mathrm{in} \mathrm{histone} \mathrm{H3} \mathrm{globular} \mathrm{domain} \mathrm{regulates} \mathrm{gene}$ expression in yeast. Cell. 2005;121(3):375-85.

11. Wei Y, Xia W, Zhang Z, Liu J, Wang H, Adsay NV, et al. Loss of trimethylation at lysine 27 of histone $\mathrm{H} 3$ is a predictor of poor outcome in breast, ovarian, and pancreatic cancers. Molecular carcinogenesis. 2008;47(9):701-6.

12. Fraga MF, Ballestar E, Villar-Garea A, Boix-Chornet M, Espada J, Schotta G, et al. Loss of acetylation at Lys 16 and trimethylation at Lys 20 of histone $\mathrm{H} 4$ is a common hallmark of human cancer. Nature genetics. 2005;37(4):391-400.

13. Barski A, Cuddapah S, Cui K, Roh TY, Schones DE, Wang Z, et al. High-resolution profiling of histone methylations in the human genome. Cell. 2007;129(4):823-37.

14. Kouzarides T. Chromatin modifications and their function. Cell. 2007;128(4):693-705.

15. Dumitrescu RG. DNA methylation and histone modifications in breast cancer. Methods in molecular biology. 2012;863:35-45.

16. Peserico A, Simone C. Physical and functional HAT/HDAC interplay regulates protein acetylation balance. Journal of biomedicine \& biotechnology. 2011;2011:371832.

17. Marmorstein R, Zhou MM. Writers and readers of histone acetylation: structure, mechanism, and inhibition. Cold Spring Harbor perspectives in biology. 2014;6(7):a018762.

18. Dhalluin C, Carlson JE, Zeng L, He C, Aggarwal AK, Zhou MM. Structure and ligand of a histone acetyltransferase bromodomain. Nature. 1999;399(6735):491-6.

19. Kim TY, Bang YJ, Robertson KD. Histone deacetylase inhibitors for cancer therapy. Epigenetics. 2006;1(1):14-23.

20. Sambucetti LC, Fischer DD, Zabludoff S, Kwon PO, Chamberlin H, Trogani N, et al. Histone deacetylase inhibition selectively alters the activity and expression of cell cycle proteins leading to specific chromatin acetylation and antiproliferative effects. The Journal of biological chemistry. 1999;274(49):34940-7. 
21. Suraweera A, O'Byrne KJ, Richard DJ. Combination Therapy With Histone Deacetylase Inhibitors (HDACi) for the Treatment of Cancer: Achieving the Full Therapeutic Potential of HDACi. Frontiers in oncology. 2018;8:92.

22. de Ruijter AJ, van Gennip $A H$, Caron HN, Kemp S, van Kuilenburg AB. Histone deacetylases (HDACs): characterization of the classical HDAC family. The Biochemical journal. 2003;370(Pt 3):737-49.

23. Seto E, Yoshida M. Erasers of histone acetylation: the histone deacetylase enzymes. Cold Spring Harbor perspectives in biology. 2014;6(4):a018713.

24. Buggy JJ, Sideris ML, Mak P, Lorimer DD, Mclntosh B, Clark JM. Cloning and characterization of a novel human histone deacetylase, HDAC8. The Biochemical journal. 2000;350 Pt 1:199-205.

25. Yang XJ, Gregoire S. Class II histone deacetylases: from sequence to function, regulation, and clinical implication. Molecular and cellular biology. 2005;25(8):2873-84.

26. Fischle W, Dequiedt F, Hendzel MJ, Guenther MG, Lazar MA, Voelter W, et al. Enzymatic activity associated with class II HDACS is dependent on a multiprotein complex containing HDAC3 and SMRT/NCoR. Molecular cell. 2002;9(1):45-57.

27. McKinsey TA, Zhang CL, Olson EN. Activation of the myocyte enhancer factor-2 transcription factor by calcium/calmodulin-dependent protein kinase-stimulated binding of 14-3-3 to histone deacetylase 5. Proceedings of the National Academy of Sciences of the United States of America. 2000;97(26):14400-5.

28. Boyault C, Sadoul K, Pabion M, Khochbin S. HDAC6, at the crossroads between cytoskeleton and cell signaling by acetylation and ubiquitination. Oncogene. 2007;26(37):5468-76.

29. Kawaguchi Y, Kovacs JJ, McLaurin A, Vance JM, Ito A, Yao TP. The deacetylase HDAC6 regulates aggresome formation and cell viability in response to misfolded protein stress. Cell. 2003;115(6):727-38.

30. Aldana-Masangkay GI, Sakamoto KM. The role of HDAC6 in cancer. Journal of biomedicine \& biotechnology. 2011;2011:875824.

31. Vannini A, Volpari C, Gallinari P, Jones P, Mattu M, Carfi A, et al. Substrate binding to histone deacetylases as shown by the crystal structure of the HDAC8-substrate complex. EMBO reports. 2007;8(9):879-84.

32. Lahm A, Paolini C, Pallaoro M, Nardi MC, Jones $\mathrm{P}$, Neddermann $\mathrm{P}$, et al. Unraveling the hidden catalytic activity of vertebrate class lla histone deacetylases. Proceedings of the National Academy of Sciences of the United States of America. 2007;104(44):17335-40.

33. Lee $\mathrm{H}$, Rezai-Zadeh $\mathrm{N}$, Seto $\mathrm{E}$. Negative regulation of histone deacetylase 8 activity by cyclic AMP-dependent protein kinase A. Molecular and cellular biology. 2004;24(2):765-73.

34. Frye RA. Phylogenetic classification of prokaryotic and eukaryotic Sir2-like proteins. Biochemical and biophysical research communications. 2000;273(2):793-8.

35. Vaziri H, Dessain SK, Ng Eaton E, Imai SI, Frye RA, Pandita TK, et al. hSIR2(SIRT1) functions as an NAD-dependent p53 deacetylase. Cell. 2001;107(2):149-59.

36. Brunet A, Sweeney LB, Sturgill JF, Chua KF, Greer PL, Lin Y, et al. Stress-dependent regulation of FOXO transcription factors by the SIRT1 deacetylase. Science. 2004;303(5666):2011-5.

37. Motta MC, Divecha N, Lemieux M, Kamel C, Chen D, Gu W, et al. Mammalian SIRT1 represses forkhead transcription factors. Cell. 2004;116(4):551-63.

38. North BJ, Marshall BL, Borra MT, Denu JM, Verdin E. The human Sir2 ortholog, SIRT2, is an NAD+-dependent tubulin deacetylase. Molecular cell. 2003;11(2):437-44.

39. Rodgers JT, Lerin C, Haas W, Gygi SP, Spiegelman BM, Puigserver P. Nutrient control of glucose homeostasis through a complex of PGC-1alpha and SIRT1. Nature. 2005;434(7029):113-8.

40. Hallows WC, Lee S, Denu JM. Sirtuins deacetylate and activate mammalian acetyl-CoA synthetases. Proceedings of the National Academy of Sciences of the United States of America. 2006;103(27):10230-5. 
41. Schwer B, Bunkenborg J, Verdin RO, Andersen JS, Verdin E. Reversible lysine acetylation controls the activity of the mitochondrial enzyme acetyl-CoA synthetase 2. Proceedings of the National Academy of Sciences of the United States of America. 2006;103(27):10224-9.

42. Starai VJ, Celic I, Cole RN, Boeke JD, Escalante-Semerena JC. Sir2-dependent activation of acetylCoA synthetase by deacetylation of active lysine. Science. 2002;298(5602):2390-2.

43. Lombard DB, Alt FW, Cheng HL, Bunkenborg J, Streeper RS, Mostoslavsky R, et al. Mammalian Sir2 homolog SIRT3 regulates global mitochondrial lysine acetylation. Molecular and cellular biology. 2007;27(24):8807-14.

44. Du J, Zhou Y, Su X, Yu JJ, Khan S, Jiang H, et al. Sirt5 is a NAD-dependent protein lysine demalonylase and desuccinylase. Science. 2011;334(6057):806-9.

45. Yuan H, Marmorstein R. Structural basis for sirtuin activity and inhibition. The Journal of biological chemistry. 2012;287(51):42428-35.

46. Millard CJ, Watson PJ, Celardo I, Gordiyenko Y, Cowley SM, Robinson CV, et al. Class I HDACs share a common mechanism of regulation by inositol phosphates. Molecular cell. 2013;51(1):57-67.

47. Turnbull RE, Fairall L, Saleh A, Kelsall E, Morris KL, Ragan TJ, et al. The MiDAC histone deacetylase complex is essential for embryonic development and has a unique multivalent structure. Nature communications. 2020;11(1):3252.

48. Watson PJ, Millard CJ, Riley AM, Robertson NS, Wright LC, Godage HY, et al. Insights into the activation mechanism of class I HDAC complexes by inositol phosphates. Nature communications. 2016;7:11262.

49. Millard CJ, Fairall L, Ragan TJ, Savva CG, Schwabe JWR. The topology of chromatin-binding domains in the NuRD deacetylase complex. Nucleic acids research. 2020;48(22):12972-82.

50. Bressi JC, Jennings AJ, Skene R, Wu Y, Melkus R, De Jong R, et al. Exploration of the HDAC2 foot pocket: Synthesis and SAR of substituted $\mathrm{N}$-(2-aminophenyl)benzamides. Bioorganic \& medicinal chemistry letters. 2010;20(10):3142-5.

51. Wagner FF, Weiwer M, Steinbacher S, Schomburg A, Reinemer P, Gale JP, et al. Kinetic and structural insights into the binding of histone deacetylase 1 and 2 (HDAC1, 2) inhibitors. Bioorganic \& medicinal chemistry. 2016;24(18):4008-15.

52. Liu J, Yu Y, Kelly J, Sha D, Alhassan AB, Yu W, et al. Discovery of Highly Selective and Potent HDAC3 Inhibitors Based on a 2-Substituted Benzamide Zinc Binding Group. ACS medicinal chemistry letters. 2020;11(12):2476-83.

53. Clausen DJ, Liu J, Yu W, Duffy JL, Chung CC, Myers RW, et al. Development of a selective HDAC inhibitor aimed at reactivating the HIV latent reservoir. Bioorganic \& medicinal chemistry letters. 2020;30(17):127367.

54. Yu W, Liu J, Yu Y, Zhang V, Clausen D, Kelly J, et al. Discovery of ethyl ketone-based HDACs 1, 2, and 3 selective inhibitors for HIV latency reactivation. Bioorganic \& medicinal chemistry letters. 2020;30(13):127197.

55. Lauffer BE, Mintzer R, Fong R, Mukund S, Tam C, Zilberleyb I, et al. Histone deacetylase (HDAC) inhibitor kinetic rate constants correlate with cellular histone acetylation but not transcription and cell viability. The Journal of biological chemistry. 2013;288(37):26926-43.

56. Fournier JF, Bhurruth-Alcor Y, Musicki B, Aubert J, Aurelly M, Bouix-Peter C, et al. Squaramides as novel class I and IIB histone deacetylase inhibitors for topical treatment of cutaneous $t$-cell lymphoma. Bioorganic \& medicinal chemistry letters. 2018;28(17):2985-92.

57. Liu J, Kelly J, Yu W, Clausen D, Yu Y, Kim H, et al. Selective Class I HDAC Inhibitors Based on Aryl Ketone Zinc Binding Induce HIV-1 Protein for Clearance. ACS medicinal chemistry letters. 2020;11(7):1476-83.

58. Watson PJ, Fairall L, Santos GM, Schwabe JW. Structure of HDAC3 bound to co-repressor and inositol tetraphosphate. Nature. 2012;481(7381):335-40. 
59. Vannini A, Volpari C, Filocamo G, Casavola EC, Brunetti M, Renzoni D, et al. Crystal structure of a eukaryotic zinc-dependent histone deacetylase, human HDAC8, complexed with a hydroxamic acid inhibitor. Proceedings of the National Academy of Sciences of the United States of America. 2004;101(42):15064-9.

60. Dowling DP, Gattis SG, Fierke CA, Christianson DW. Structures of metal-substituted human histone deacetylase 8 provide mechanistic inferences on biological function. Biochemistry. 2010;49(24):5048-56.

61. Somoza JR, Skene RJ, Katz BA, Mol C, Ho JD, Jennings AJ, et al. Structural snapshots of human HDAC8 provide insights into the class I histone deacetylases. Structure. 2004;12(7):1325-34.

62. Dowling DP, Gantt SL, Gattis SG, Fierke CA, Christianson DW. Structural studies of human histone deacetylase 8 and its site-specific variants complexed with substrate and inhibitors. Biochemistry. 2008;47(51):13554-63.

63. Whitehead L, Dobler MR, Radetich B, Zhu Y, Atadja PW, Claiborne T, et al. Human HDAC isoform selectivity achieved via exploitation of the acetate release channel with structurally unique small molecule inhibitors. Bioorganic \& medicinal chemistry. 2011;19(15):4626-34.

64. Porter NJ, Christianson DW. Binding of the Microbial Cyclic Tetrapeptide Trapoxin A to the Class I Histone Deacetylase HDAC8. ACS chemical biology. 2017;12(9):2281-6.

65. Tabackman AA, Frankson R, Marsan ES, Perry K, Cole KE. Structure of 'linkerless' hydroxamic acid inhibitor-HDAC8 complex confirms the formation of an isoform-specific subpocket. Journal of structural biology. 2016;195(3):373-8.

66. Cole KE, Dowling DP, Boone MA, Phillips AJ, Christianson DW. Structural basis of the antiproliferative activity of largazole, a depsipeptide inhibitor of the histone deacetylases. Journal of the American Chemical Society. 2011;133(32):12474-7.

67. Park SY, Kim GS, Hwang HJ, Nam TH, Park HS, Song J, et al. Structural basis of the specific interaction of SMRT corepressor with histone deacetylase 4. Nucleic acids research. 2018;46(22):1177688.

68. Bottomley MJ, Lo Surdo P, Di Giovine P, Cirillo A, Scarpelli R, Ferrigno F, et al. Structural and functional analysis of the human HDAC4 catalytic domain reveals a regulatory structural zinc-binding domain. The Journal of biological chemistry. 2008;283(39):26694-704.

69. Schuetz A, Min J, Allali-Hassani A, Schapira M, Shuen M, Loppnau P, et al. Human HDAC7 harbors a class Ila histone deacetylase-specific zinc binding motif and cryptic deacetylase activity. The Journal of biological chemistry. 2008;283(17):11355-63.

70. Lobera M, Madauss KP, Pohlhaus DT, Wright QG, Trocha M, Schmidt DR, et al. Selective class Ila histone deacetylase inhibition via a nonchelating zinc-binding group. Nature chemical biology. 2013;9(5):319-25.

71. Ouyang H, Ali YO, Ravichandran M, Dong A, Qiu W, MacKenzie F, et al. Protein aggregates are recruited to aggresome by histone deacetylase 6 via unanchored ubiquitin $C$ termini. The Journal of biological chemistry. 2012;287(4):2317-27.

72. Hai Y, Christianson DW. Histone deacetylase 6 structure and molecular basis of catalysis and inhibition. Nature chemical biology. 2016;12(9):741-7.

73. Cao D, Wang M, Qiu X, Liu D, Jiang H, Yang N, et al. Structural basis for allosteric, substratedependent stimulation of SIRT1 activity by resveratrol. Genes \& development. 2015;29(12):1316-25.

74. Zhao X, Allison D, Condon B, Zhang F, Gheyi T, Zhang A, et al. The 2.5 A crystal structure of the SIRT1 catalytic domain bound to nicotinamide adenine dinucleotide (NAD+) and an indole (EX527 analogue) reveals a novel mechanism of histone deacetylase inhibition. Journal of medicinal chemistry. 2013;56(3):963-9.

75. Davenport AM, Huber FM, Hoelz A. Structural and functional analysis of human SIRT1. Journal of molecular biology. 2014;426(3):526-41. 
76. Dai H, Case AW, Riera TV, Considine T, Lee JE, Hamuro Y, et al. Crystallographic structure of a small molecule SIRT1 activator-enzyme complex. Nature communications. 2015;6:7645.

77. Moniot S, Schutkowski M, Steegborn C. Crystal structure analysis of human Sirt2 and its ADPribose complex. Journal of structural biology. 2013;182(2):136-43.

78. Gertz M, Fischer F, Nguyen GT, Lakshminarasimhan M, Schutkowski M, Weyand M, et al. Ex-527 inhibits Sirtuins by exploiting their unique NAD+-dependent deacetylation mechanism. Proceedings of the National Academy of Sciences of the United States of America. 2013;110(30):E2772-81.

79. Feldman JL, Dittenhafer-Reed KE, Kudo N, Thelen JN, Ito A, Yoshida $M$, et al. Kinetic and Structural Basis for Acyl-Group Selectivity and NAD(+) Dependence in Sirtuin-Catalyzed Deacylation. Biochemistry. 2015;54(19):3037-50.

80. You W, Zheng W, Weiss S, Chua KF, Steegborn C. Structural basis for the activation and inhibition of Sirtuin 6 by quercetin and its derivatives. Scientific reports. 2019;9(1):19176.

81. Rumpf T, Gerhardt S, Einsle O, Jung M. Seeding for sirtuins: microseed matrix seeding to obtain crystals of human Sirt3 and Sirt2 suitable for soaking. Acta crystallographica Section F, Structural biology communications. 2015;71(Pt 12):1498-510.

82. Yang LL, Wang HL, Zhong L, Yuan C, Liu SY, Yu ZJ, et al. X-ray crystal structure guided discovery of new selective, substrate-mimicking sirtuin 2 inhibitors that exhibit activities against non-small cell lung cancer cells. European journal of medicinal chemistry. 2018;155:806-23.

83. Rumpf T, Schiedel M, Karaman B, Roessler C, North BJ, Lehotzky A, et al. Selective Sirt2 inhibition by ligand-induced rearrangement of the active site. Nature communications. 2015;6:6263.

84. Sundriyal S, Moniot S, Mahmud Z, Yao S, Di Fruscia P, Reynolds CR, et al. Thienopyrimidinone Based Sirtuin-2 (SIRT2)-Selective Inhibitors Bind in the Ligand Induced Selectivity Pocket. Journal of medicinal chemistry. 2017;60(5):1928-45.

85. Ragoussis J, Senger G, Mockridge I, Sanseau P, Ruddy S, Dudley K, et al. A testis-expressed Zn finger gene (ZNF76) in human 6p21.3 centromeric to the MHC is closely linked to the human homolog of the t-complex gene tcp-11. Genomics. 1992;14(3):673-9.

86. Yamagata K, Goto Y, Nishimasu H, Morimoto J, Ishitani R, Dohmae N, et al. Structural basis for potent inhibition of SIRT2 deacetylase by a macrocyclic peptide inducing dynamic structural change. Structure. 2014;22(2):345-52.

87. Mellini P, Itoh Y, Tsumoto H, Li Y, Suzuki M, Tokuda N, et al. Potent mechanism-based sirtuin-2selective inhibition by an in situ-generated occupant of the substrate-binding site, "selectivity pocket" and NAD(+)-binding site. Chemical science. 2017;8(9):6400-8.

88. Teng YB, Jing H, Aramsangtienchai P, He B, Khan S, Hu J, et al. Efficient demyristoylase activity of SIRT2 revealed by kinetic and structural studies. Scientific reports. 2015;5:8529.

89. Moniot S, Forgione M, Lucidi A, Hailu GS, Nebbioso A, Carafa V, et al. Development of 1,2,4Oxadiazoles as Potent and Selective Inhibitors of the Human Deacetylase Sirtuin 2: Structure-Activity Relationship, X-ray Crystal Structure, and Anticancer Activity. Journal of medicinal chemistry. 2017;60(6):2344-60.

90. Jin L, Wei W, Jiang Y, Peng H, Cai J, Mao C, et al. Crystal structures of human SIRT3 displaying substrate-induced conformational changes. The Journal of biological chemistry. 2009;284(36):24394405.

91. Nguyen GT, Gertz M, Steegborn C. Crystal structures of Sirt3 complexes with 4'-bromoresveratrol reveal binding sites and inhibition mechanism. Chemistry \& biology. 2013;20(11):1375-85.

92. Gai W, Li H, Jiang H, Long Y, Liu D. Crystal structures of SIRT3 reveal that the alpha2-alpha3 loop and alpha3-helix affect the interaction with long-chain acyl lysine. FEBS letters. 2016;590(17):3019-28.

93. Nguyen GT, Schaefer S, Gertz M, Weyand M, Steegborn C. Structures of human sirtuin 3 complexes with ADP-ribose and with carba-NAD+ and SRT1720: binding details and inhibition mechanism. Acta crystallographica Section D, Biological crystallography. 2013;69(Pt 8):1423-32. 
94. Disch JS, Evindar G, Chiu CH, Blum CA, Dai H, Jin L, et al. Discovery of thieno[3,2-d]pyrimidine-6carboxamides as potent inhibitors of SIRT1, SIRT2, and SIRT3. Journal of medicinal chemistry. 2013;56(9):3666-79.

95. Yang LL, Wang HL, Yan YH, Liu S, Yu ZJ, Huang MY, et al. Sensitive fluorogenic substrates for sirtuin deacylase inhibitor discovery. European journal of medicinal chemistry. 2020;192:112201.

96. Rajabi N, Auth M, Troelsen KR, Pannek M, Bhatt DP, Fontenas M, et al. Mechanism-Based Inhibitors of the Human Sirtuin 5 Deacylase: Structure-Activity Relationship, Biostructural, and Kinetic Insight. Angewandte Chemie. 2017;56(47):14836-41.

97. Szczepankiewicz BG, Dai H, Koppetsch KJ, Qian D, Jiang F, Mao C, et al. Synthesis of carba-NAD and the structures of its ternary complexes with SIRT3 and SIRT5. The Journal of organic chemistry. 2012;77(17):7319-29.

98. Gertz M, Nguyen GT, Fischer F, Suenkel B, Schlicker C, Franzel B, et al. A molecular mechanism for direct sirtuin activation by resveratrol. PloS one. 2012;7(11):e49761.

99. Wang H-L, Liu S, Yu Z-J, Wu C, Cheng L, Wang Y, et al. Interactions between sirtuins and fluorogenic small-molecule substrates offer insights into inhibitor design. RSC Advances. 2017;7(58):36214-22.

100. Pan PW, Feldman JL, Devries MK, Dong A, Edwards AM, Denu JM. Structure and biochemical functions of SIRT6. The Journal of biological chemistry. 2011;286(16):14575-87.

101. You W, Rotili D, Li TM, Kambach C, Meleshin M, Schutkowski M, et al. Structural Basis of Sirtuin 6 Activation by Synthetic Small Molecules. Angewandte Chemie. 2017;56(4):1007-11.

102. Huang Z, Zhao J, Deng W, Chen Y, Shang J, Song K, et al. Identification of a cellularly active SIRT6 allosteric activator. Nature chemical biology. 2018;14(12):1118-26.

103. You W, Steegborn C. Structural Basis of Sirtuin 6 Inhibition by the Hydroxamate Trichostatin A: Implications for Protein Deacylase Drug Development. Journal of medicinal chemistry. 2018;61(23):10922-8.

104. Priyanka A, Solanki V, Parkesh R, Thakur KG. Crystal structure of the N-terminal domain of human SIRT7 reveals a three-helical domain architecture. Proteins. 2016;84(10):1558-63.

105. Hassig CA, Tong JK, Fleischer TC, Owa T, Grable PG, Ayer DE, et al. A role for histone deacetylase activity in HDAC1-mediated transcriptional repression. Proceedings of the National Academy of Sciences of the United States of America. 1998;95(7):3519-24.

106. Finnin MS, Donigian JR, Cohen A, Richon VM, Rifkind RA, Marks PA, et al. Structures of a histone deacetylase homologue bound to the TSA and SAHA inhibitors. Nature. 1999;401(6749):188-93.

107. Schapira M. Structural biology of human metal-dependent histone deacetylases. Handbook of experimental pharmacology. 2011;206:225-40.

108. Miyake $Y$, Keusch JJ, Wang L, Saito M, Hess D, Wang X, et al. Structural insights into HDAC6 tubulin deacetylation and its selective inhibition. Nature chemical biology. 2016;12(9):748-54.

109. Moniot S, Weyand M, Steegborn C. Structures, substrates, and regulators of Mammalian sirtuins - opportunities and challenges for drug development. Frontiers in pharmacology. 2012;3:16.

110. Chakrabarty SP, Balaram H. Reversible binding of zinc in Plasmodium falciparum Sir2: structure and activity of the apoenzyme. Biochimica et biophysica acta. 2010;1804(9):1743-50.

111. Prasad GS, Sridhar V, Yamaguchi M, Hatefi Y, Stout CD. Crystal structure of transhydrogenase domain III at 1.2 A resolution. Nature structural biology. 1999;6(12):1126-31.

112. Pannek M, Simic Z, Fuszard M, Meleshin M, Rotili D, Mai A, et al. Crystal structures of the mitochondrial deacylase Sirtuin 4 reveal isoform-specific acyl recognition and regulation features. Nature communications. 2017;8(1):1513.

113. Feng W, Lu Z, Luo RZ, Zhang X, Seto E, Liao WS, et al. Multiple histone deacetylases repress tumor suppressor gene ARHI in breast cancer. International journal of cancer. 2007;120(8):1664-8. 
114. Park SY, Jun JA, Jeong KJ, Heo HJ, Sohn JS, Lee HY, et al. Histone deacetylases 1,6 and 8 are critical for invasion in breast cancer. Oncology reports. 2011;25(6):1677-81.

115. Yu Y, Xu F, Peng H, Fang X, Zhao S, Li Y, et al. NOEY2 (ARHI), an imprinted putative tumor suppressor gene in ovarian and breast carcinomas. Proceedings of the National Academy of Sciences of the United States of America. 1999;96(1):214-9.

116. Zhang Z, Yamashita H, Toyama T, Sugiura H, Omoto $Y$, Ando $Y$, et al. HDAC6 expression is correlated with better survival in breast cancer. Clinical cancer research : an official journal of the American Association for Cancer Research. 2004;10(20):6962-8.

117. Hervouet E, Claude-Taupin A, Gauthier T, Perez V, Fraichard A, Adami P, et al. The autophagy GABARAPL1 gene is epigenetically regulated in breast cancer models. BMC cancer. 2015;15:729.

118. Ray A, Alalem M, Ray BK. Loss of epigenetic Kruppel-like factor 4 histone deacetylase (KLF-4HDAC)-mediated transcriptional suppression is crucial in increasing vascular endothelial growth factor (VEGF) expression in breast cancer. The Journal of biological chemistry. 2013;288(38):27232-42.

119. Esteller M. Cancer epigenomics: DNA methylomes and histone-modification maps. Nature reviews Genetics. 2007;8(4):286-98.

120. Peterson TJ, Karmakar S, Pace MC, Gao T, Smith CL. The silencing mediator of retinoic acid and thyroid hormone receptor (SMRT) corepressor is required for full estrogen receptor alpha transcriptional activity. Molecular and cellular biology. 2007;27(17):5933-48.

121. Yao R, Jiang $H$, Ma Y, Wang L, Wang L, Du J, et al. PRMT7 induces epithelial-to-mesenchymal transition and promotes metastasis in breast cancer. Cancer research. 2014;74(19):5656-67.

122. Huang Y, Vasilatos SN, Boric L, Shaw PG, Davidson NE. Inhibitors of histone demethylation and histone deacetylation cooperate in regulating gene expression and inhibiting growth in human breast cancer cells. Breast cancer research and treatment. 2012;131(3):777-89.

123. Muller BM, Jana L, Kasajima A, Lehmann A, Prinzler J, Budczies J, et al. Differential expression of histone deacetylases HDAC1, 2 and 3 in human breast cancer--overexpression of HDAC2 and HDAC3 is associated with clinicopathological indicators of disease progression. BMC cancer. 2013;13:215.

124. Lapierre M, Linares A, Dalvai M, Duraffourd C, Bonnet S, Boulahtouf A, et al. Histone deacetylase 9 regulates breast cancer cell proliferation and the response to histone deacetylase inhibitors. Oncotarget. 2016;7(15):19693-708.

125. Shan W, Jiang Y, Yu H, Huang Q, Liu L, Guo X, et al. HDAC2 overexpression correlates with aggressive clinicopathological features and DNA-damage response pathway of breast cancer. American journal of cancer research. 2017;7(5):1213-26.

126. Chalkiadaki A, Guarente L. The multifaceted functions of sirtuins in cancer. Nature reviews Cancer. 2015;15(10):608-24.

127. George J, Ahmad N. Mitochondrial Sirtuins in Cancer: Emerging Roles and Therapeutic Potential. Cancer research. 2016;76(9):2500-6.

128. Vasilatos SN, Katz TA, Oesterreich S, Wan Y, Davidson NE, Huang Y. Crosstalk between lysinespecific demethylase 1 (LSD1) and histone deacetylases mediates antineoplastic efficacy of HDAC inhibitors in human breast cancer cells. Carcinogenesis. 2013;34(6):1196-207.

129. West AC, Johnstone RW. New and emerging HDAC inhibitors for cancer treatment. The Journal of clinical investigation. 2014;124(1):30-9.

130. Roche J, Bertrand P. Inside HDACs with more selective HDAC inhibitors. European journal of medicinal chemistry. 2016;121:451-83.

131. Gu W, Nusinzon I, Smith RD, Jr., Horvath CM, Silverman RB. Carbonyl- and sulfur-containing analogs of suberoylanilide hydroxamic acid: Potent inhibition of histone deacetylases. Bioorganic \& medicinal chemistry. 2006;14(10):3320-9. 
132. Saito A, Yamashita T, Mariko Y, Nosaka Y, Tsuchiya K, Ando T, et al. A synthetic inhibitor of histone deacetylase, MS-27-275, with marked in vivo antitumor activity against human tumors. Proceedings of the National Academy of Sciences of the United States of America. 1999;96(8):4592-7.

133. Mottamal M, Zheng S, Huang TL, Wang G. Histone deacetylase inhibitors in clinical studies as templates for new anticancer agents. Molecules. 2015;20(3):3898-941.

134. Tan J, Cang S, Ma Y, Petrillo RL, Liu D. Novel histone deacetylase inhibitors in clinical trials as anti-cancer agents. Journal of hematology \& oncology. 2010;3:5.

135. Shultz MD, Cao X, Chen CH, Cho YS, Davis NR, Eckman J, et al. Optimization of the in vitro cardiac safety of hydroxamate-based histone deacetylase inhibitors. Journal of medicinal chemistry. 2011;54(13):4752-72.

136. Robertson FM, Chu K, Boley KM, Ye Z, Liu H, Wright MC, et al. The class I HDAC inhibitor Romidepsin targets inflammatory breast cancer tumor emboli and synergizes with paclitaxel to inhibit metastasis. Journal of experimental therapeutics \& oncology. 2013;10(3):219-33.

137. Jiang Z, Li W, Hu X, Zhang Q, Sun T, Cui S, et al. Tucidinostat plus exemestane for postmenopausal patients with advanced, hormone receptor-positive breast cancer (ACE): a randomised, double-blind, placebo-controlled, phase 3 trial. The Lancet Oncology. 2019;20(6):806-15.

138. Connolly RM, Rudek MA, Piekarz R. Entinostat: a promising treatment option for patients with advanced breast cancer. Future oncology. 2017;13(13):1137-48.

139. Connolly RM, Zhao F, Miller KD, Lee M-J, Piekarz RL, Smith KL, et al. Abstract GS4-02: E2112: Randomized phase 3 trial of endocrine therapy plus entinostat/placebo in patients with hormone receptor-positive advanced breast cancer. A trial of the ECOG-ACRIN cancer research group. Cancer research. 2021;81(4 Supplement):GS4-02-GS4-.

140. Pan D, Lu X. New therapeutic avenue of epigenetic modulations in cancer. Translational Breast Cancer Research. 2020;1.

141. Li Y, Seto E. HDACs and HDAC Inhibitors in Cancer Development and Therapy. Cold Spring Harbor perspectives in medicine. 2016;6(10).

142. Milazzo G, Mercatelli D, Di Muzio G, Triboli L, De Rosa P, Perini G, et al. Histone Deacetylases (HDACs): Evolution, Specificity, Role in Transcriptional Complexes, and Pharmacological Actionability. Genes. 2020;11(5).

143. Seo J, Min SK, Park HR, Kim DH, Kwon MJ, Kim LS, et al. Expression of Histone Deacetylases HDAC1, HDAC2, HDAC3, and HDAC6 in Invasive Ductal Carcinomas of the Breast. Journal of breast cancer. 2014;17(4):323-31.

144. Yi Z, Wenwen L, Kun W, Jian S. [Overexpression of histone deacetylase 11 suppresses basal-like breast cancer cell invasion and metastasis]. Nan fang yi ke da xue xue bao = Journal of Southern Medical University. 2019;39(7):751-9.

145. Desouki MM, Doubinskaia I, Gius D, Abdulkadir SA. Decreased mitochondrial SIRT3 expression is a potential molecular biomarker associated with poor outcome in breast cancer. Human pathology. 2014;45(5):1071-7.

146. Hsieh HY, Chuang HC, Shen FH, Detroja K, Hsin LW, Chen CS. Targeting breast cancer stem cells by novel HDAC3-selective inhibitors. European journal of medicinal chemistry. 2017;140:42-51.

147. An P, Chen F, Li Z, Ling Y, Peng Y, Zhang $\mathrm{H}$, et al. HDAC8 promotes the dissemination of breast cancer cells via AKT/GSK-3ß/Snail signals. Oncogene. 2020;39(26):4956-69.

148. Yu SL, Lee DC, Son JW, Park CG, Lee HY, Kang J. Histone deacetylase 4 mediates SMAD family member 4 deacetylation and induces 5 -fluorouracil resistance in breast cancer cells. Oncology reports. 2013;30(3):1293-300.

149. Li A, Liu Z, Li M, Zhou S, Xu Y, Xiao Y, et al. Correction: HDAC5, a potential therapeutic target and prognostic biomarker, promotes proliferation, invasion and migration in human breast cancer. Oncotarget. 2017;8(18):30619-20. 
150. Caslini C, Hong S, Ban YJ, Chen XS, Ince TA. HDAC7 regulates histone 3 lysine 27 acetylation and transcriptional activity at super-enhancer-associated genes in breast cancer stem cells. Oncogene. 2019;38(39):6599-614.

151. Jin X, Wei Y, Xu F, Zhao M, Dai K, Shen R, et al. SIRT1 promotes formation of breast cancer through modulating Akt activity. Journal of Cancer. 2018;9(11):2012-23.

152. Shah AA, Ito A, Nakata A, Yoshida M. Identification of a Selective SIRT2 Inhibitor and Its Antibreast Cancer Activity. Biological \& pharmaceutical bulletin. 2016;39(10):1739-42.

153. Huang G, Lin Y, Zhu G. SIRT4 is upregulated in breast cancer and promotes the proliferation, migration and invasion of breast cancer cells. International journal of clinical and experimental pathology. 2017;10(12):11849-56.

154. Greene KS, Lukey MJ, Wang X, Blank B, Druso JE, Lin MJ, et al. SIRT5 stabilizes mitochondrial glutaminase and supports breast cancer tumorigenesis. Proceedings of the National Academy of Sciences of the United States of America. 2019.

155. Becherini P, Caffa I, Piacente F, Damonte P, Vellone VG, Passalacqua M, et al. SIRT6 enhances oxidative phosphorylation in breast cancer and promotes mammary tumorigenesis in mice. Cancer \& metabolism. 2021;9(1):6.

156. Chen KL, Li L, Yang FX, Li CM, Wang YR, Wang GL. SIRT7 depletion inhibits cell proliferation, migration, and increases drug sensitivity by activating $\mathrm{p} 38 \mathrm{MAPK}$ in breast cancer cells. Journal of cellular physiology. 2018;233(9):6767-78.

157. Cao F, Zwinderman MRH, Dekker FJ. The Process and Strategy for Developing Selective Histone Deacetylase 3 Inhibitors. Molecules. 2018;23(3).

158. Marek M, Shaik TB, Heimburg T, Chakrabarti A, Lancelot J, Ramos-Morales E, et al. Characterization of Histone Deacetylase 8 (HDAC8) Selective Inhibition Reveals Specific Active Site Structural and Functional Determinants. Journal of medicinal chemistry. 2018;61(22):10000-16.

159. Tang W, Luo T, Greenberg EF, Bradner JE, Schreiber SL. Discovery of histone deacetylase 8 selective inhibitors. Bioorganic \& medicinal chemistry letters. 2011;21(9):2601-5.

160. Huang WJ, Wang YC, Chao SW, Yang CY, Chen LC, Lin MH, et al. Synthesis and biological evaluation of ortho-aryl N-hydroxycinnamides as potent histone deacetylase (HDAC) 8 isoform-selective inhibitors. ChemMedChem. 2012;7(10):1815-24.

161. Maolanon AR, Madsen AS, Olsen CA. Innovative Strategies for Selective Inhibition of Histone Deacetylases. Cell chemical biology. 2016;23(7):759-68.

162. Houtkooper RH, Pirinen E, Auwerx J. Sirtuins as regulators of metabolism and healthspan. Nature reviews Molecular cell biology. 2012;13(4):225-38.

163. Zhou Z, Ma T, Zhu Q, Xu Y, Zha X. Recent advances in inhibitors of sirtuin1/2: an update and perspective. Future medicinal chemistry. 2018;10(8):907-34.

164. Cen Y. Sirtuins inhibitors: the approach to affinity and selectivity. Biochimica et biophysica acta. 2010;1804(8):1635-44.

165. Chowdhury S, Sripathy S, Webster A, Park A, Lao U, Hsu JH, et al. Discovery of Selective SIRT2 Inhibitors as Therapeutic Agents in B-Cell Lymphoma and Other Malignancies. Molecules. 2020;25(3).

166. Peck B, Chen CY, Ho KK, Di Fruscia P, Myatt SS, Coombes RC, et al. SIRT inhibitors induce cell death and p53 acetylation through targeting both SIRT1 and SIRT2. Molecular cancer therapeutics. 2010;9(4):844-55.

167. Neugebauer RC, Uchiechowska U, Meier R, Hruby H, Valkov V, Verdin E, et al. Structure-activity studies on splitomicin derivatives as sirtuin inhibitors and computational prediction of binding mode. Journal of medicinal chemistry. 2008;51(5):1203-13.

168. Vaidya GN, Rana P, Venkatesh A, Chatterjee DR, Contractor D, Satpute DP, et al. Paradigm shift of "classical" HDAC inhibitors to "hybrid" HDAC inhibitors in therapeutic interventions. European journal of medicinal chemistry. 2021;209:112844. 
169. Li C, Tang C, Hu Z, Zhao C, Li C, Zhang S, et al. Synthesis and structure-activity relationships of novel hybrid ferrocenyl compounds based on a bicyclic core skeleton for breast cancer therapy. Bioorganic \& medicinal chemistry. 2016;24(13):3062-74.

170. Tang C, Li C, Zhang S, Hu Z, Wu J, Dong C, et al. Novel Bioactive Hybrid Compound Dual Targeting Estrogen Receptor and Histone Deacetylase for the Treatment of Breast Cancer. Journal of medicinal chemistry. 2015;58(11):4550-72.

171. Patel HK, Siklos MI, Abdelkarim H, Mendonca EL, Vaidya A, Petukhov PA, et al. A chimeric SERMhistone deacetylase inhibitor approach to breast cancer therapy. ChemMedChem. 2014;9(3):602-13.

172. Pulya S, Amin SA, Adhikari N, Biswas S, Jha T, Ghosh B. HDAC6 as privileged target in drug discovery: A perspective. Pharmacological research. 2021;163:105274.

\section{Figure legends:}

Figure 1: Multiple sequence alignment of HDAC catalytic domains using Clustal Omega. (A) Zinc dependent HDACs from classes I, IIa, IIb, and IV. Conserved key catalytic amino acid residues are highlighted in red, and residues involved in acetyl-lysine peptide binding are colored in pink. Green residues indicated amino acid substitutions and residues in blue can be targeted for isoform-selective inhibition. Loops involved in substrate binding for deacetylase activity are boxed in red labelled from L1 to L4. The two catalytic domains of HDAC6 have been aligned as HDAC6_1 andHDAC6_2. (B) NAD+ dependent class III HDACs. Residues that participate in NAD+ binding are colored in red, pink residues are involved in acetyl-lysine peptide-binding, and marked in purple are the residues involved in zinc binding. Solid lines beneath the sequence alignment indicate which regions of the proteins compose the Rossmannfold domain (red), cofactor binding loop (green), and Zinc binding domain (blue). The last two lines show consensus secondary structures (Consensus_ss) where $\alpha$-helix is denoted by h and $\beta$ strand by e.

Figure 2: Class-representative PDB structures to highlight structural differences in HDAC catalytic domains. A) Zinc dependent HDACs from classes I (HDAC1; PDB: 4BKX), IIa (HDAC7; PDB: 3COZ), and IIb (HDAC6; PDB: 5EDU). Secondary structure elements of catalytic fold are coded in light orange ( $\alpha$ - helix), deep teal ( $\beta$ - sheets), and raspberry (loops) color. Four loops involved in catalytic activity are labeled from L1 to L4. A dashed line is representative of juxtaposed arrangement of two catalytic domains of HDAC6, with CD2 involved in deacetylase activity. B) NAD+ dependent class III SIRTs from sub-classes I (SIRT1; PDB: 5BTR), III (SIRT5; PDB: 3RIG), and IV (SIRT6; PDB: 3PKI). Catalytic Rossmann- fold is colored in magenta, with branching loops represented in yellow connecting it to the zinc-binding domain coded in blue, and the cofactor binding loop in green. 
Figure 1:

L1

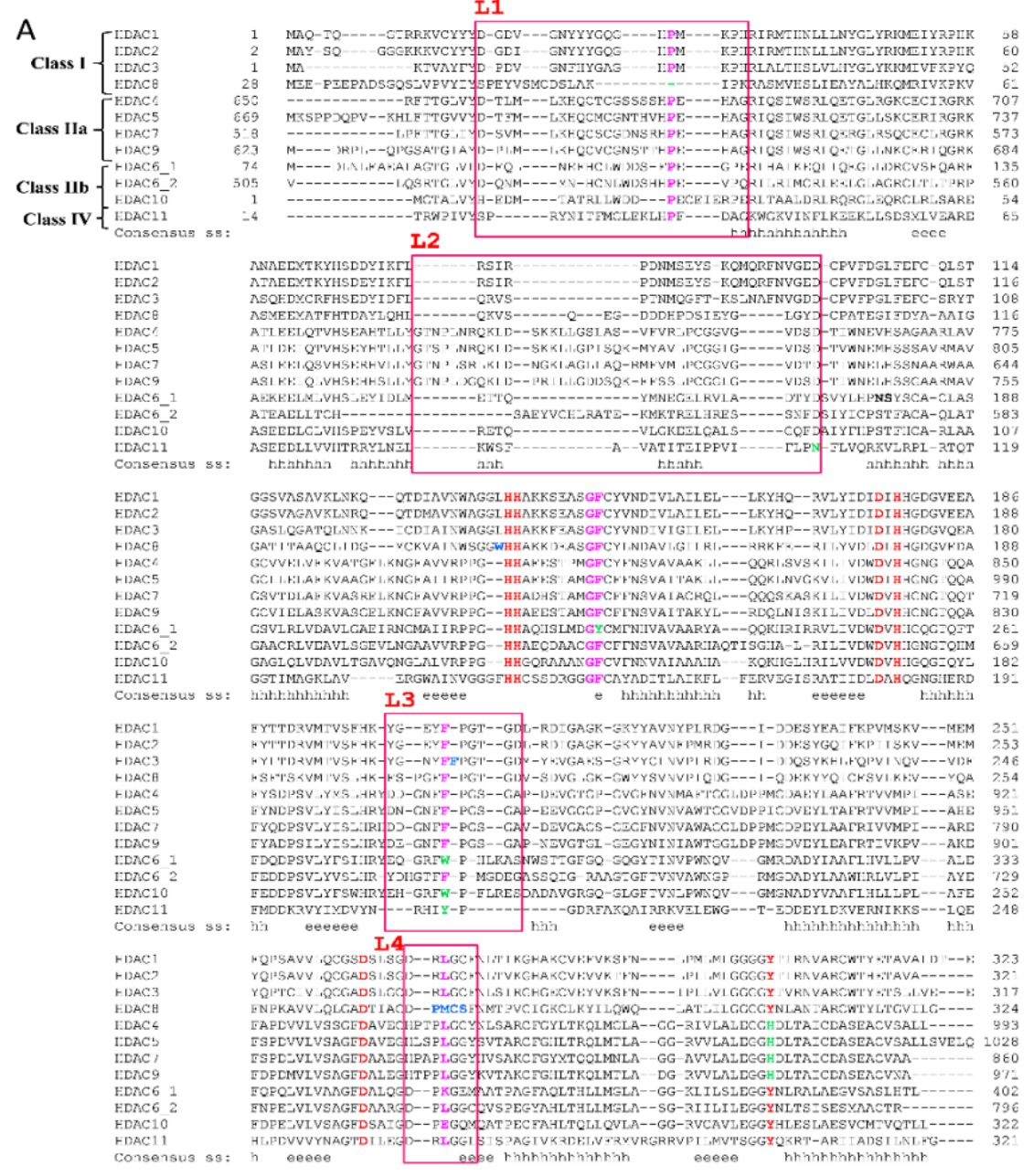

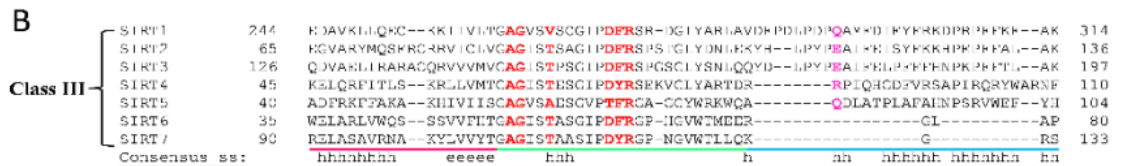

SIRT 1 --EIYPGQFQPSICAKFIAL SDXE----GKLIRNYTQNIDIIEQVAGIQ--RI IQCHGSFATASCLICKYKVDCEAVRG 385

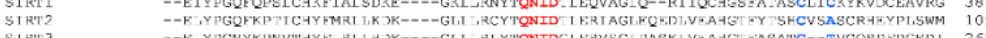

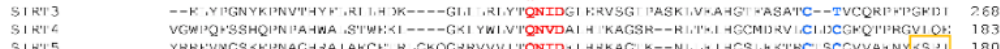

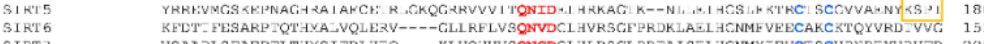

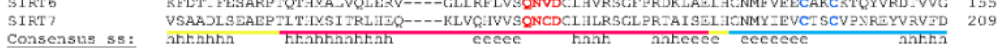

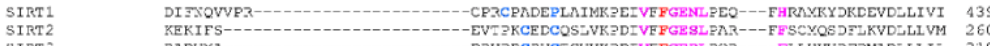

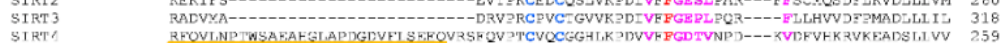

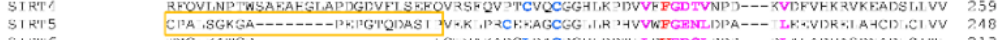

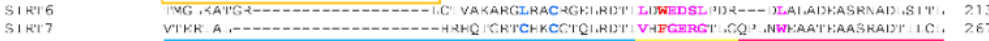

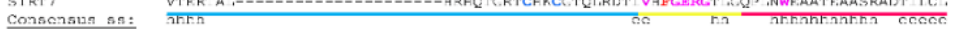

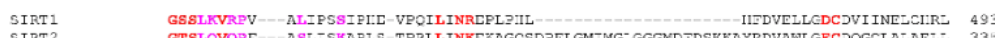
SIRT 3
SIRT 1 GTSLEVEF

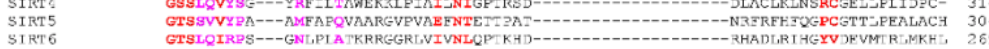

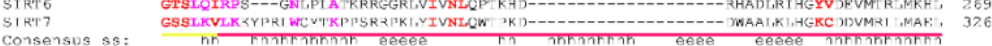


Figure 2:
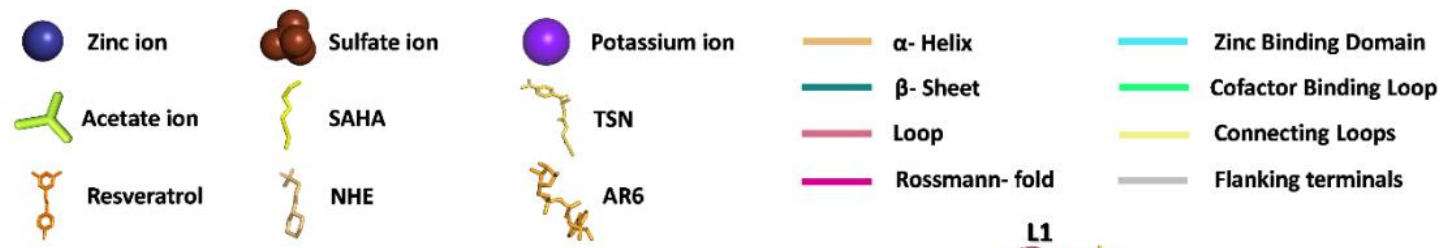

A.

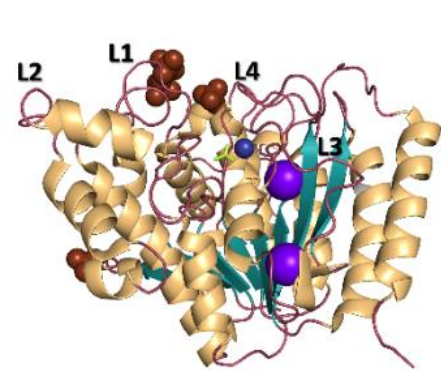

Class I
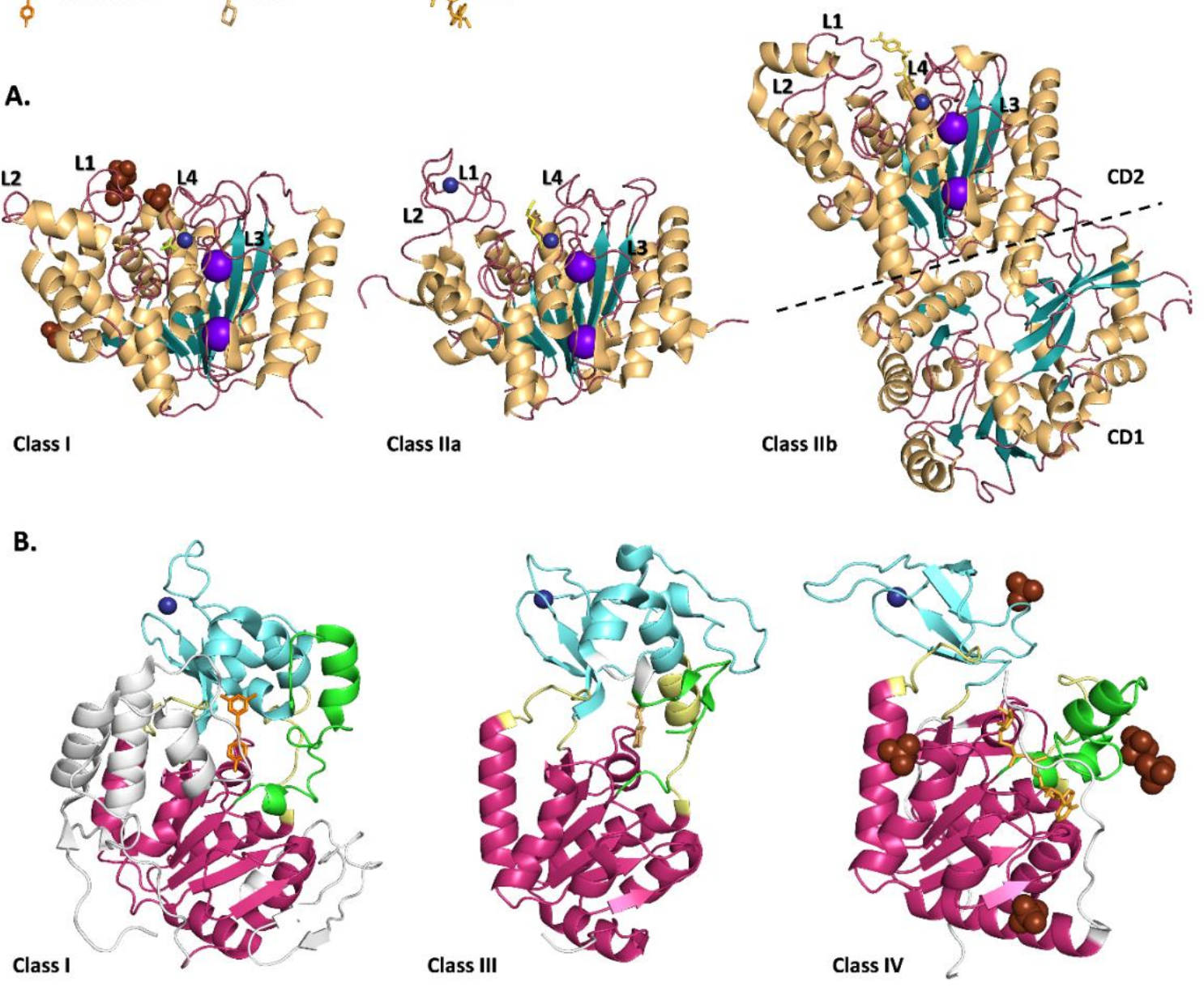